\title{
REVOLUCIÓN CHILENA, LITORAL BOLIVIANO: La Patria, la Compañía de Salitres y los prolegómenos de la Guerra del Pacífico en el Desierto de Atacama (1870-1879)
}

\author{
Alonso BARROS \\ Fundación Desierto de Atacama (Chile) \\ alonso.barros.v@gmail.com
}

CHILEAN REVOLUTION, BOLIVIAN COAST: The Homeland League and the Antofagasta Nitrate \& Railway Company in the run-up to the War of the Pacific in the Atacama Desert (18701879)

Resumen: En octubre de 1876 se constituye en Antofagasta la Sociedad de Socorros Mutuos "La Patria" como reacción a la situación social y económica imperante en Bolivia bajo la dictadura de Hilarión Daza, especialmente difícil para los colonos asentados en la costa árida del Departamento litoral de Atacama y en el pujante mineral de plata de Caracoles, en su mayoría chilenos. La Patria reunió a la casi totalidad de los patrones y obreros residentes extranjeros y algunos bolivianos y llevó adelante un movimiento regional independentista y federalista inspirado en el ejemplo californiano. Los aprestos revolucionarios fueron momentáneamente interrumpidos por la rebelión del coronel boliviano Rufino Carrasco y luego, definitivamente, con el terremoto y maremoto de 9 de Mayo de 1877, y no se retomaron hasta el estallido de la guerra. El análisis del papel que jugó La Patria y la gravitación del mineral de Caracoles en el imaginario Abstract: proto-nacional, así como del rol logístico de la Compañía de Salitres y Ferrocarriles de Antofagasta en la guerra, demuestran la equivalencia estructural entre el imperialismo europeo decimonónico, la expansión colonial chilena y otras guerras internacionales americanas de la época, pero ante todo, la importancia de los incipientes sentimientos regionalistas y xenófobos alimentados por el capitalismo de imprenta. Este artículo propone una re-lectura de la guerra, informada por hechos que la historiografía nacional suele relegar a un segundo plano. La industrialización acelerada, la colonización masiva en tierras con débil presencia estatal y el nuevo giro colonial de la mentalidad europea y estadunidense, se tradujeron en Chile en un regionalismo criollo afín a los sucesos de California. La conclusión analiza el rol estructurante del

Palabras clave: discurso racial entre los beligerantes y en los escritos e imaginarios de la guerra.

The "Homeland Friendly Society" was formed in Antofagasta in October 1876, in reaction to the social and economic situation prevailing under Hilarion Daza's military dictatorship, which was especially hard to the Chilean workers who settled in Bolivia's arid Littoral Department of Atacama and on the inland town of Caracoles with its booming silver placers. The Homeland League virtually brought together the totality of foreign residents, patrons and workers, and a few Bolivians, into a federalist regional independence movement inspired by California's previous decades' Bear-Flag independence from Mexico. Revolutionary preparations were momentarily interrupted by Bolivian Colonel Rufino Carrasco's rebellion and altogether stopped with the advent of the major earthquake and tsunami of 9 may 1877. The analysis of the role played by the League, the importance of Caracoles' silver in the proto-national imaginations, and the crucial logistic support that the Antofagasta Nitrate and Railway Company gave to Chile during the war, helps to highlight the structural equivalence between nineteenth century European imperialism, Chile's own colonial expansion, and other interamerican wars of the time, but foremost, the importance of early xenophobe sentiments spurred by racialized print-capitalism. The conclusion re-reads the American Southern Cone's War of the Pacific, as informed through facts that Chile's nationalmilitaristic historiography usually relegates to a second plane. Accelerated industrialization, massive colonization in lands with weak Bolivian presence and the new colonial turn undertaken by Europe and the USA, shows how such regionalist feelings rose alongside racialized discourses between the warring parties, in the writings and imaginaries that prefaced the war.

Guerra del Pacífico. Bolivia. Antofagasta. Desierto de Atacama. Historia regional War of the Pacific. Bolivia. Antofagasta. Atacama Desert. Regional History 
'Me resta hablaros de nuestras relaciones con las potencias estranjeras. Y tengo la satisfacción de deciros que los combates con las tribus bárbaras del Sur en la primera época de mi administración, y la guerra contra la Confederación Perúboliviana, han sido las únicas interrupciones de la paz exterior en el espacio de diez años'

(Exposición a la Nación del Presidente Prieto, 1841)

'Bajo el punto puramente indígena y comarcano habría sido, a la verdad, cosa tan imposible evitar que el litoral boliviano fuese con corta diferencia de años, territorio chileno, como lo habría sido treinta años antes alcanzar que las Californias hubiesen permanecido bajo la bandera de Méjico, después del descubrimiento del oro y de la ocupación civil ejecutada por los americanos del Oeste' (Vicuña 1880: 23).

\section{Introducción: la colonización del imaginario en el Desierto de Atacama ${ }^{1}$}

Durante la primera mitad del s. XIX Chile apenas si pasaba de Copiapó por el Norte o del Río Bío Bío hacia el sur. Más allá, la imaginación territorial de las autoridades políticas chilenas se ceñía a la guerra en fronteras inciertas. Sin duda que la geopolítica portaliana que impuso la hegemonía de Valparaíso en el Pacífico Suramericano había tenido mucho éxito (Ortega 1984, 2006; Barros 2009), tanto, que el salitre llegó a ser conocido mundialmente como "Salitre de Chile", siendo que la producción mundial de salitre se concentraba entonces en Tarapacá. En las salitreras peruanas, eso sí, trabajaba una 'población flotante' de masa migrante, sobre todo chilena, que se echaba a rondar empobrecida tras cada crisis, bonanzas y quiebras.

Mientras, entre Tal-Tal y la desembocadura del Loa, los puertos y los establecimientos mineros de la costa boliviana y los oasis del Loa y de la puna de Atacama, lograban imponer lentamente y con sobresaltos un importante arreo y tráfico de comercio y contrabando (Cajías, 1975, Löfstrom, 1991, Barros, 2008). De tradición multisecular, tales actividades decaían repetidamente hasta la inopia y el aislamiento, impedidas por el sinfín de guerras y guerrillas de independencia, civiles, montoneras e internacionales que atravesaron todo la Provincia Litoral de Atacama, especialmente durante las primeras seis décadas del siglo (Cajías, 1975, Cavieres 2007, Barros, 2008, 2007a).

Es así que los yacimientos hallados por chilenos en las Salinas del Carmen (cerca de Antofagasta) y en Tal-Tal, pusieron rápidamente en peligro el monopolio construido afanosamente por el gobierno, influyendo en los precios y especulaciones internacionales, y poniendo en peligro los contratos de suministro suscritos entre el Perú y grandes casas comerciales como la casa Dreyfuss. La población migrante chilena se fue asentando en Antofagasta y Caracoles, que se convirtieron rápidamente en populosas ciudades. Aunque estos procesos recuerdan los de décadas anteriores de auge en Coquimbo y Atacama (Ortega y Rubio 2006), también existen paralelos interesantes con la fiebre del oro ocurrida en California durante la primera mitad del siglo, que atrajo contingentes de patrones y cuadrillas de

1Proyecto FONDECYT N 11060534 “Discriminación, identidad y desigualdad en períodos de crisis: etnohistoria juridico-política de San Pedro de Atacama y Chiu-Chiu (s. 19-21)". Agradecimientos a la London School of Economics and Political Sciences por otorgarme un semestre sabático en el año 2012 y a l'Institut d'Études Avancées de Nantes por haberme acogido y contribuido a financiar parte de la investigación durante ese período. 


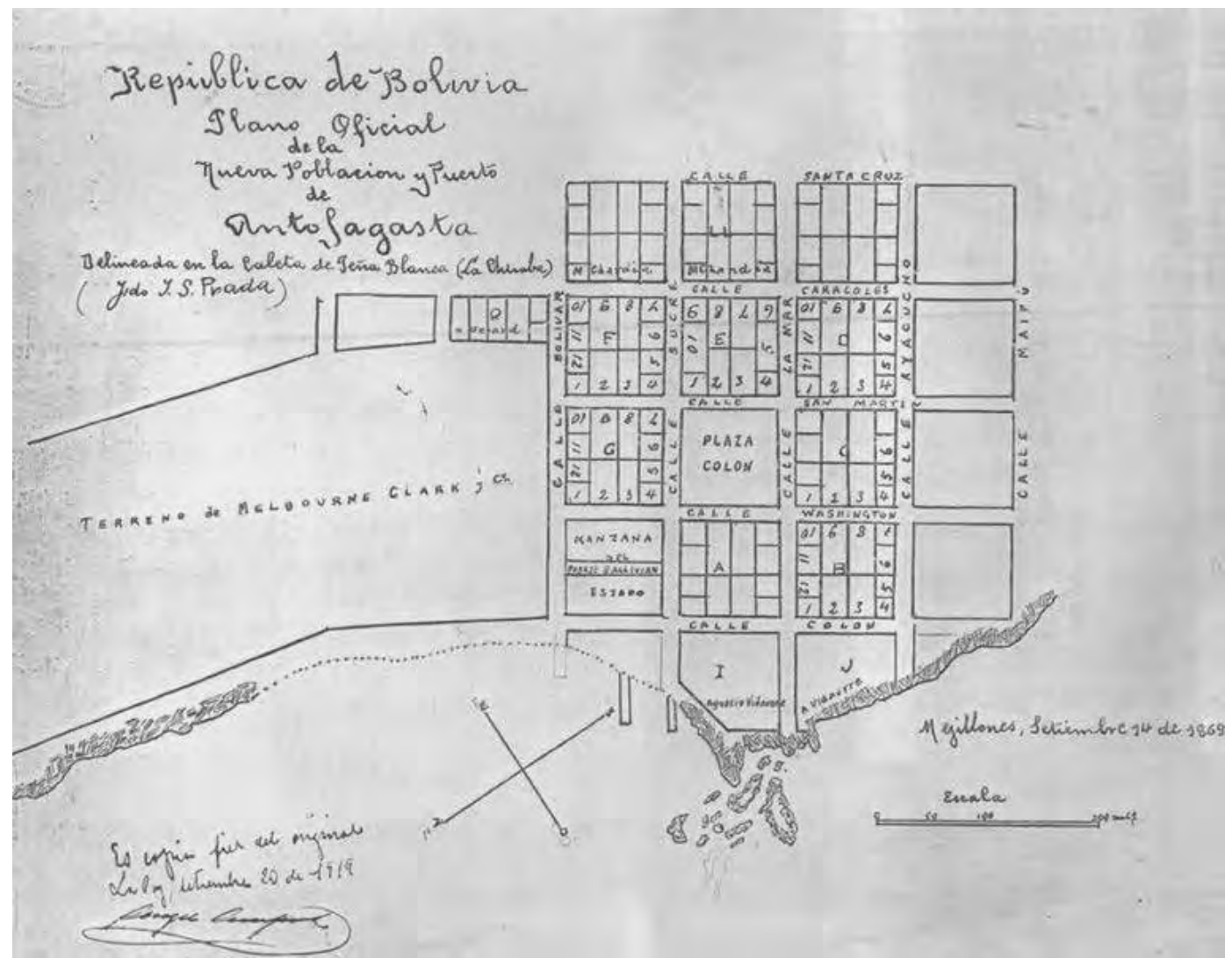

Fig. 1 Plano Oficial de la Nueva Población y Puerto de Antofagasta delineada en la Caleta de Peña Blanca (La Chimba) J. S. Prada. Mejillones Septiembre 14 de 1869 (En Cruz, 1966).

obreros chilenos, por decenas de miles, que fueron discriminados y expulsados del naciente Estado norteamericano (Purcell).

Situación sin precedentes en la Historia de Chile, la marejada humana que inundó el desierto de Atacama por la Costa, el Sur y el Norte, sobrepasó la capacidad de policía boliviana, empujando cada vez más la demanda de recursos en el hinterland desértico y altiplánico, de oasis y de puna.

Manuel Ravest reseña dos corrientes historiográficas principales sobre la Guerra del Pacífico. La primera, más cercana a los eventos (Ortega, 1984, 2006) explica la guerra de conquista como "último recurso" a que acudió la elite chilena para impedir que el Perú consolidara su monopolio del salitre con apoyo boliviano. Claramente, el remate de la Compañía de Salitres y Ferrocarril de Antofagasta (en adelante CSFA), que las autoridades bolivianas habían previsto llevar a cabo el catorce de febrero de 1879, iba a dejar fuera del negocio a la pujante elite mercantil y financiera anglo-chilena, con profundos efectos desestabilizadores para todo el país. Desoyendo el eco de la lucha por el control hegemónico del comercio marítimo en el Pacífico (que llevó a la guerra de los tres países durante la fase mercantilista de principios de siglo); y, tras las lecciones aprendidas de la desastrosa guerra "Americana" dudosamente llevada por los aliados en contra España (1866), esta vez la oligarquía peruana quiso imponer y no "compartir" su gigantesco "destino manifiesto" minero, que se venía encarnando en los lucrativos retornos del guano y del salitre. Al menos, no quería compartir dichos beneficios con la pujante oligarquía chilena, encarnada en la CSFA, controlada por los Edwards y sus socios en Londres, Santiago y Valparaíso. 
A esta elite chilena, civiles y militares confundidos, importaba entonces directamente asegurar el control sobre los activos mineros atacameños y tarapaqueños, hasta el trance de la guerra si necesario. Menos conocido, el monopolio del yodo en manos inglesas, sería otro de los notables resultados financieros de la guerra (Crozier).

Tras rechazar Hilarión Daza la propuesta chilena de arbitraje conforme al tratado de 1874, los accionistas chilenos (ministros y diputados, civiles y militares), acudieron a la guerra como último arbitrio que para evitar la reventa boliviana del salitre de Atacama en beneficio del monopolio del Perú. Tal como lo señala Ortega, esa influyente élite no cejó hasta acabar con el monopolio peruano y establecer el de ellos. Tuvo además otros motivos de satisfacción: el Gerente de la CSFA, George Hicks, no perdió ocasión de anunciar que un oportuno desembarque chileno y la guerra "haría subir las acciones [de la CSFA] más del 200 porciento y más".

La segunda corriente interpretativa analiza la economía política global en que se desarrolló la Guerra con un prisma de inspiración marxista internacionalista. Muestra convincentemente a la GDP como a un producto del capitalismo periférico que matrimoniaba las oligarquías sudamericanas con el capital inglés, en función de expandir los intereses económicos de los países de Europa, no sin antes revestirlos de un delgado ropaje nacional.

En una línea posmoderna, publicaciones recientes describen la Guerra del Pacífico como a una fatalidad que debe ser comprendida en cuanto efecto del "capitalismo de imprenta", sobre todo en su expresión racista, como si ésta fuera definitoria del movimiento social chileno en guerra (véase, por ejemplo, Hobsbawm The Age of Empire). Sin embargo, la caracterización original de Anderson se refería más bien al surgimiento del zeitgeist independentista latinoamericano; y Ortega, entre otros, ya destacó este rol creciente de la prensa nacionalista, financiada desde la CFSA y periódicos como El Ferrocarril y la Patria. Se aprecia fácilmente el esquema estructurante de la mentalidad chilena de la época, en que el Estado y la prensa eran controlados por una elite que jugó la moderna carta nacionalpopulista con eficacia, con vocación expansiva, afín al contexto colonizador global en que se enfrascaron todas las potencias mundiales de entonces. Los autores postmodernos, en cambio, muestran los dispositivos raciales desplegados en esta guerra de republiquetas, como a una "suplantación" o remedo oligárquico al repertorio racial imperial, copiado de Europa, en ningún caso, original, autoreferente o endógeno (Beckman, 2008, 2009). Según esta versión, el racismo sudamericano no tendría rasgos autóctonos, si no que sería un pálido remedo de lo que ocurría en Europa.

Retomando a Ravest, podemos considerar que tales versiones postmodernas tienen el defecto de echar a un lado los "factores jurídicos y del honor y dignidad nacional comprometidos en la infracción del Pacto [de 1874]" (Ravest, 2008: 65).

Pero si los beligerantes tenían una noción similar de "honor" y "dignidad" nacional vinculada al zeitgeist romántico decadente de los duelos de moda en Europa ¿Por qué se expresó ese incipiente "honor nacional" de los criollos sudamericanos en términos raciales? ¿Por qué culminó en guerra "fratricida"? ¿Cuál es el vínculo estructurante entre el proceso nacionalizador de la guerra y el racismo -cada vez más xenofóbico?

El crecimiento de la "mutua desconfianza”, antes y después de la guerra ¿Por qué y cómo se naturalizó en la clave racial que hasta ahora estigmatiza las relaciones entre vecinos, soterrada en la xenofobia?².

La nacionalidades que recortó la prensa populista programada por la elite, redujo en parte la historia territorial, una que a mi juicio no ha merecido suficiente atención y que es la que aquí pretendo esbozar. El contraste de las perspectivas historiográficas nacional (dog-

2 Cavieres es particularmnete lúcido respecto a la genealogía y la arqueo-geopolítica de la "mutua desconfianza" en Sudamérica (2007). En este artículo retoma algunos de los aspectos más explícitamente racializados de los textos, que perduran en el imaginario colectivo contemporáneo. 
mática) y racial (reflexiva) puede explicar en parte lo que a mi juicio le da cuerpo a sentimientos nacionales con un sello xenófobo conosuramericano. El corolario mediático-racial de los movimientos migratorios (cíclicamente amarrados a crisis mineras vinculados a los mayores intereses financieros) fue uno de los principales motores ideológicos del conflicto.

Aunque pueda afirmarse que la Guerra del Pacífico consolidó el popular "honor" nacional como proyecto de la élite (Grez, etc), no debe dejarse de lado la importancia que para el "teatro de la Guerra" tuvo el discurso racial mestizo-criollo (de cholos, rotos y cuicos), emanado de las prensas de Argentina, Bolivia, Chile y Perú. El espíritu nacional de las elites criollas se forjó con las prensas. Progresivamente, la violencia anti-española llevada por la elite criolla a su máxima expresión más "americanista" en la guerra de 1866, se reinscribió en el contexto colonial internacional en contra de los mapuches primero, hacia el sur (como en el epígrafe) y luego contra las expresiones nacional-regionalistas encabezadas por los patrones de minas y sus cuadrillas ennegrecidas, frente a un orden terrateniente establecido por la antigua aristocracia del Centro (Ortega y Rubio, 2006).

Retomando la lógica aplicada al surgimiento proto-nacional, directamente vinculado a la prensa de la élite y el alfabetismo en aumento; debe entenderse que la racialización en la prensa también subtiende las divisiones y desconfianzas mutuas al interior de la castas dominantes en los cuatro países.

La prensa de guerra-mundo europea y norteamericana alimentó textos deshumanizadores en Chile; tanto coloniales como imperiales, configuran la animalización del enemigo a explotar y sacrificar en aras de lo que vino a ser una de las mayores vorágines financieras en la historia del Pacífico suramericano. La GDP reforzó una mentalidad diferenciadora de clase y raza que hunde sus raíces en tierras prehispánicas y coloniales.

La efectividad territorial de las creencias, actitudes y valores encarnados en la acción nacional chilena, se aprecia en el gran número de milicianos chilenos que integró los batallones cívicos junto a cantidad de temporeros y vagabundos, que no trepidaron en saquear a indios y blancos, arrasando la tierra a su paso. La subjetividad solevantada por la prensa populista y personajes variopintos como Benjamín Vicuña Mackenna, llevó la lucha por los recursos más allá del pequeño y encastado Chile, haciendo caso omiso del sistema legal boliviano que regía en el Desierto de Atacama. Porque la historia no la hacen solamente los escribanos militares ni los políticos de turno, que suelen producir versiones parciales. El Desierto de Atacama es un laboratorio social en condiciones extremas que son, por lo mismo, fácilmente reducibles a la observación antropológica, porque la historia es ante todo micro-historia. Los nacionalismos conosureños son el producto etnográfico de estereotipos sociales clasistas y xenofóbicos que integran el imaginario colectivo chileno actual, con su característico encastamiento de tipo neocolonial (Barros, 2008a, 2008b).

Las diferencias se desvanecen si pensamos que fueron alimentadas como parte del proyecto político esmerado en los escritos de la guerra por cada una de las elites, como de concierto.

La GDP selló también la preponderancia marítima que ostentaba Valparaíso en el Pacífico antes de la Guerra contra España (1866) re-encontrada comercial y financiera de Valparaíso en el Pacífico (por algo el salitre se conocía como "Nitratos de Chile").

En el nivel internacional, los tres futuros beligerantes dependían por igual de los ingresos mineros del Desierto de Atacama, y, por ende, de momento, de esa mano de obra de chilena, abundante, laboriosa, barata y necesitada. La marejada humana que inundó el desierto de Atacama sobrepasó a la escasa policía boliviana; y, como reseñó la estrofa anónima aparecida en un periódico de La Paz durante la guerra (en Querejazu, 1979: 280):

¿Quién armó la cachetina?

Puez la pansa del pobre roto 


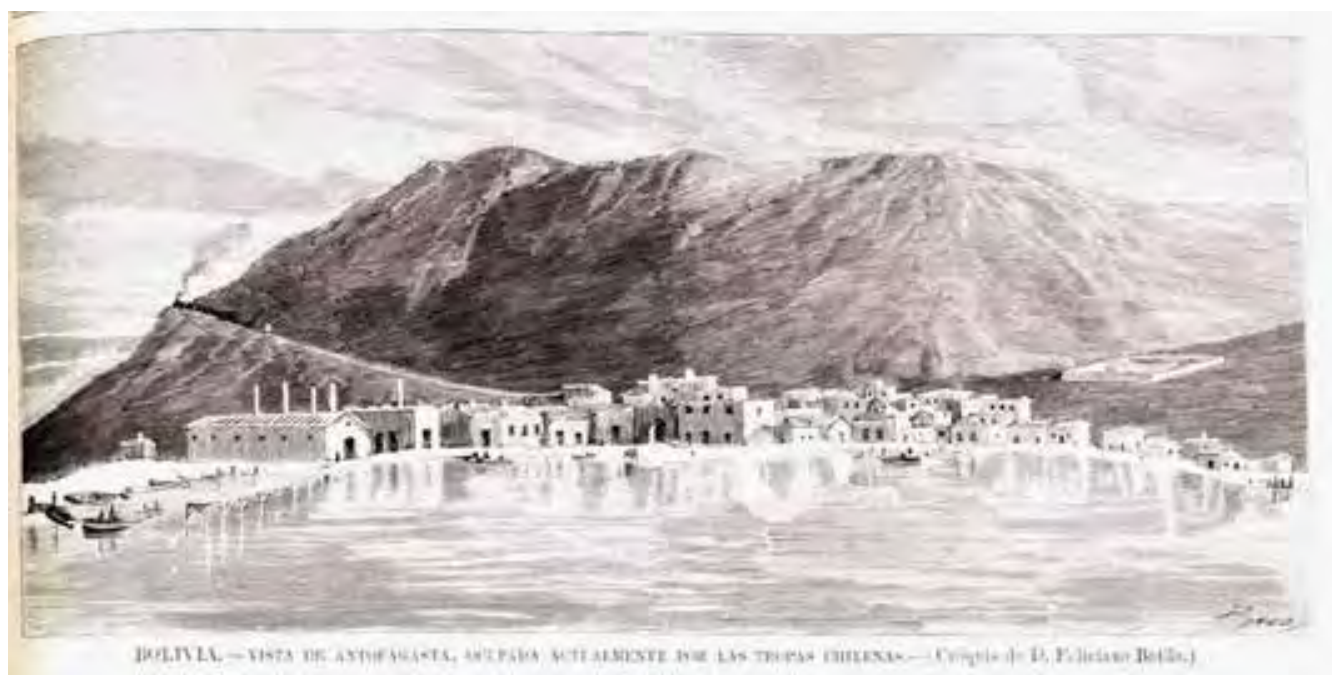

Que se ha cansado del poroto

$Y$ ahora quiere probar gallina

Un mosaico de testimonios locales y regionales deja apreciar la huella compartida del discurso clasista, racista y nacionalista en boga, parecido al que estaba entonces consolidándose en Europa y América (contra las poblaciones aborígenes de Asia, África y Australia). Pero entre Bolivia, Chile y Perú, la racialización de la xenofobia tiene su historia particular, de raigambre colonial, y tal vez, incluso, pre-colonial (Las guerras del Inka contro los Aucaruna no fueron solo un producto de la imaginación). Claro está que los hechos y discursos de la GDP contradicen el espíritu igualitario de las luces y logias de la Independencia así como el entonces revolucionario discurso de los Derechos Humanos y del ciudadano (Manceron). Pero se ajustaba de maravilla al naciente radicalismo de corte nacional-regionalista que brotaba en por entonces entre los colonos dispersos por el Pacífico ${ }^{3}$.

La pampa de Antofagasta con su condición de completa aridez, históricamente, sólo puede ser entendida desde la interrelación e interconexión que existió entre la franja litoral, las quebradas del interior y la cordillera a través del poblamiento y movilidad de distintos grupos indígenas que la recorrían en busca de diversos recursos existentes en los diferentes pisos ecológicos. Y aquella articulación persistió en tiempos de la explotación del salitre. Las rutas de tráfico ya existentes fueron esenciales para la malla de asentamientos relacionados con las nuevas actividades mineras, pues si bien en la zona de las pampas salitrales se enclavó la industria salitrera, fue la zona de las quebradas, la que abasteció a los centros productores de salitre de carbón, leña, forraje, productos agrícolas, además de mulares procedentes del Noroeste argentino (Bermúdez, 1963: 17). También fue clave el tendido de líneas férreas que permitió la comunicación no sólo de los distintos enclaves y asentamientos. Sino que también posibilitó la vinculación de aquellos con el área de la cordillera marítima en donde se abrieron y/o habilitaron puertos para la internación de productos y mercancías procedentes del centro-sur de Chile, de Europa, Estados Unidos y Australia, entre otros; además del embarque del nitrato hacia los mercados extranjeros (Ibid.).

"De Calama viajan a Huanchaca 120 carretas con cuatro mulas cada una. De Calama a Cobija viajan también veinte carretas con igual dotación de

3 En Chile se retomaban lentamente debates europeos que ya evidenciaban la inmoralidad colonizadora y su contradicción con los Derechos Humanos, cuya formulación contaba más de cien años. Vd. Manceron 2007. 
mulas. Ambas tropas acarrean víveres y mercaderías al interior y se proveen de forrajes de Caracoles, Cobija y Tocopilla... En Calama y Chiu-Chiu hay grandes existencias de llamas que los indios comen y usan como bestias de carga. También hay ovejas de grandes rebaños traídos de la República Argentina y que engordan para remitir a Caracoles y a la Costa. Atacama es el único punto de paso de los ganados arjentinos y el lugar obligado de descanso y pastaje. De ahí pasan a pastar a Calama los que siguen viaje al norte hasta Perú. Hay también entre Calama y Chiu-Chiu cerca de 600 mulas de carga que viajan a Potosí... Entre Calama y Chiu-Chiu habrán como 2000 habitantes y en Atacama cerca de 1000 más o menos. El cultivo de alfalfa produce cuatro cortes de alfalfa en Calama al año y solo dos en Chiu-Chiu a causa de las heladas. En Atacama se dan hasta tres cortes. El agua potable es buena en Atacama y Chiu-Chiu pero mala en Calama. La gente acomodada hace traer agua para beber de unas ocho leguas más arriba, punto de la confluencia del Río Salado que descompone el agua del Loa".

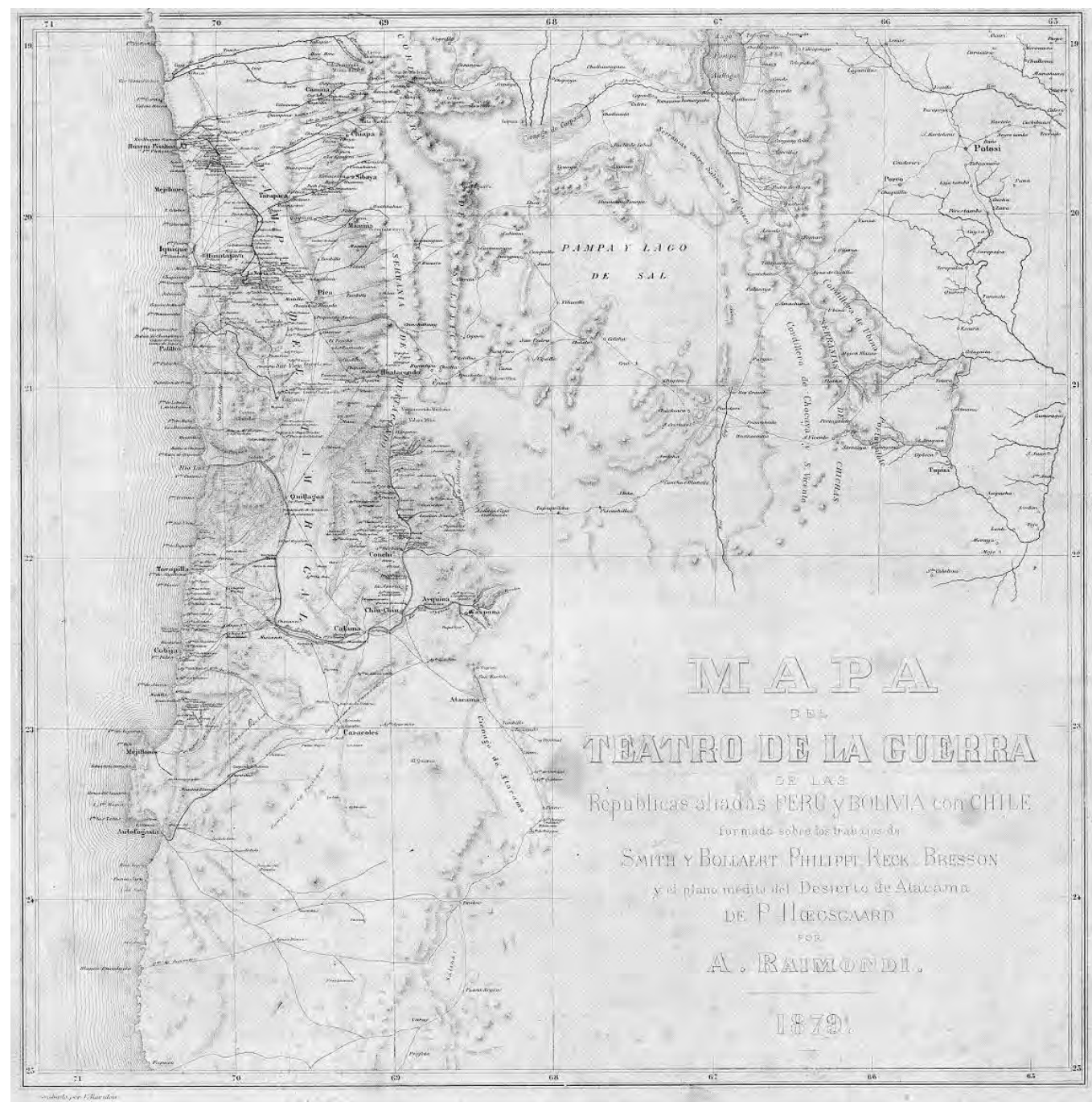


Las historias y relatos muestran parte del tejido de la vida social del desierto en guerra, en la voz de dos de sus principales referentes sociales: la Sociedad de Socorros Mutuos "La Patria" (en adelante La Patria) y la CSFA.

Desde entonces, el racismo chileno y surandino se mantiene, insidioso y solapado, a la vez vergonzante y orgulloso, alimentando las férreas entrañas de la negación en su intertexto. Y este imaginario racializado fue en su momento un 'secreto a voces' que impregnaba también a la masa trabajadora chilena, gran parte de ella proveniente del deprimido Norte Chico, o huida de California, unas décadas antes, o de un Tarapacá peruano crecientemente hostil, una masa relativamente educada, necesitada y arribista, en una nueva tierra de oportunidades (Serrano "Historia de la educación en Chile"). Se olvida muy menudo que, de haberse ejecutado el remate, el populacho también hubiera quedado, literalmente, de patitas en la calle...

La mutua desconfianza boliviano-chilena fue particularmente odiosa previo al tratado de límites de 1874 (llegando Bolivia y Perú incluso a firmar en 1873, un tratado secreto de alianza en contra de Chile). Según la documentación peruana, Bolivia incluso pensó ofrecerle a Argentina el Litoral de Atacama para inducirla a la alianza contra Chile, (lo que no prosperó a pesar de haber el Congreso Argentino ratificado el tratado en cuestión) (Vicuña 1880). Chile por su parte también había ofrecido, en reiteradas ocasiones, tanto a Perú como a Bolivia y Argentina, alianzas guerreras en contra de uno u otro, siempre con prendas territoriales de por medio. Todos presionaban por redibujar los límites sudamericanos del Uti Possidetis, como había ocurrido ya con la Guerra de la Triple Alianza contra Paraguay (1864-1870).

Esto se tradujo en el aumento las tensiones locales en contra de los mineros y obreros chilenos que desembarcaban en Antofagasta o llegaban por tierra de Copiapó y Tarapacá. 30 años antes, habían migrado y entrado en la fiesta del guano peruano y del oro californiano, esparcidos por las costas del Pacífico: ahora sus hijos volvían por salitre y plata, muy a mano. La masa de cuadrillas, trabajadores y aventureros atrapada por el primer distrito de la guerra, era en su mayoría compuesta de pioneros, calicheros, mineros, artesanos, comerciantes, gerentes, patrones e industriales chilenos, todos ciertamente preocupados por la pérdida de trabajo, inversiones y propiedades, ante los abusos y arbitrariedades de las facciones bolivianas. Pero también porque brotó entre ellos un sentimiento pionero, al borde del voluntarismo nacionalista, fácilmente transmutado en racismo frente al injusto poder.

Benjamín Vicuña Mackenna da claves adicionales para comprender etnográficamente la máquina de guerra racializada que se armó en el pujante Distrito de Atacama boliviano -costa, valle, sierra y puna. Publicó su 'Historia de la Campaña de Tarapacá' estando la guerra en pleno desarrollo, abordando "en caliente" sus causas y efectos inmediatos, a partir de las mentalidades, informaciones privadas y hechos 'periodísticos' de la época, plasmados en cancioneros, conversaciones, gacetas, oficios, epístolas y telegramas, principalmente desde Santiago, Valparaíso, Iquique, Antofagasta y Caracoles.

Los historiadores coinciden que la colonia chilena no manifestó animadversión particular hacia los bolivianos al principio de la oleada migratoria. Fantasía independentista al alcance de la mano, el ambiente revolucionario organizado por La Patria gatilló una parte de la guerra. La horda 'araucano-chilena' de rotos menesterosos, era duramente menospreciada por las elites bolivianas, peruanas y... chilenas. El caso es que el torbellino colonial y postcolonial globalizado de fines del siglo XIX zamarreó la cuádruple frontera. El imperialismo competitivo estaba para guerras por límites, como las que provocaban cíclicamente las crisis mineras en la Costa, Pampa, Desierto y Puna de Atacama. Daza derramó la gota que rebalsó el mar. 


\section{Corvo, penca y mal gobierno: represión boliviana, descontento social y surgimiento de la Sociedad La Patria en Antofagasta y Caracoles (1872-1879) ${ }^{4}$}

"para fijar los límites del desierto, tendremos que afilar nuestros
instrumentos de mensura, los Corvos, y probarlos en la lanza Boliviana"

(Atribuido a Benjamín Vicuña Mackenna, 1854, Paz Soldán,

El mineral de Caracoles fue descubierto en marzo de 1870 y se convirtió rápidamente en un bullente campamento minero de 20.000 habitantes en pleno desierto (Arce, 1930: 343). Dos años después, se calculaban las existencias de los negocios establecidos en más de 6 millones de pesos 5 . El agua traída en carretas desde Calama, Chiu-Chiu, Limón Verde y Antofagasta, se vendía a precios exorbitantes, mientras la especulación alcanzaba un umbral inaudito. Bravo considera justamente que estos elementos son importantes para comprender el avance económico y territorial que precedió la conquista militar chilena (Bravo 2008: 20). 1500 carretas aseguraban el tráfico de personas y bienes entre Antofagasta y Caracoles.

"La gente vivía allí, al principio, de cualquier manera, la mayor parte en carpas de saco, pero luego los comerciantes de mayores recursos empezaron a construir casas de madera y de calaminas" (Arce, 1930: 244).

En plena bonanza del interior, asume la Prefectura de Cobija Don Ruperto Fernández, salteño que según Vicuña era "enérgico, pero avieso y solapado": buen número de los antiguos habitantes del desierto eran arrieros argentinos. Se vieron los primeros síntomas de lucha:

"no entre una parte de la población y la otra, como en el antiguo Potosí y en el moderno San Francisco, no entre dos razas ni dos elementos reacios o civilizadores, sino simplemente entre las masas chilenas y los soldados de Bolivia” (Vicuña, 1880a: 25).

Recuentos de la época sostienen que la chispa que encendió la hoguera revolucionaria entre los pioneros y colonos chilenos fue producto de una visita del prefecto boliviano a Caracoles, el día domingo 27 de abril de 1872, cuando se produjo una riña callejera entre mineros chilenos, donde unos cuantos formaron el corro vociferante, propio de los pugilatos a brazo y cuchillo. Ante el tumulto, abrió fuego el piquete boliviano al mando de Fernández, disparando sobre los curiosos y transeúntes, sin aviso, cayendo fatalmente Clemente Andrade, natural de Coquimbo.

Nombrado cónsul de Chile el 2 de febrero de ese año, el administrador principal de las más ricas minas de Caracoles, Enrique Villegas, había recibido el exequátur boliviano para su misión consular apenas unas horas antes de estallar la riña. Cuando Villegas le pide explicaciones formales al prefecto Fernández, éste último contesta que la autopsia había determinado que Andrade había sido muerto accidentalmente por otro chileno en fuga, explicación que fue considerada como una burla cruel $^{6}$. Un mes después del asesinato de

4 La reseña que sigue se basa en los trabajos de Benjamín Vicuña, Francisco Machuca e Isaac Arce.

5 Carmen Gloria Bravo ha cubierto con acuciosa profundidad el ciclo de vida completo del mineral de Caracoles (Bravo 2001 y 2008).

6 Enrique Villegas Encalada (Quillota, 15/7/1839- Viña del Mar 14/7/1916) trabajó en la minería desde niño, primero en Chañarcillo y luego para Escobar, Ossa y Cía., trasladándose al interior de Antofagasta apenas descubierto mineral de Caracoles. Es nombrado cónsul en 1872 y forma la sociedad La Patria en 1876. Durante 
Andrade, el sub-prefecto de Caracoles mandó azotar a Juan de Dios Araya y Amador Berríos. El cónsul Villegas intentó esta vez alguna reparación satisfactoria para los chilenos, pero el sub prefecto contestó que a ambos les estaba vedado tener injerencia en cosas de justicia, aseverando que, de todos modos, el castigo de los dos chilenos no había pasado de "una ligera corrección", según, por la insolencia de haber sacado, en su presencia, revólver y puñal corvo.

En su informe al ministro de Relaciones Exteriores de Chile, sin embargo, Villegas afirma haber examinado a los hombres flagelados "viendo por sus propios ojos que habian sido inhumanamente castigados, y que el sub prefecto había faltado a la verdad". Para él, la mejor prueba de la gratuita brutalidad que acostumbraba la policía boliviana y de la inocencia de los mineros, era que éstos fueron puestos en libertad inmediatamente después de haber recibido los azotes. Villegas temía un alzamiento de indignación en la población y en consecuencia, severas represalias por parte de los soldados:

"Se tenía como un hecho evidente en aquellos momentos que la autoridad [boliviana] estaba resuelta a formar cuadro con sus tropas y fusilar públicamente en la plaza de ese mineral a nueve ciudadanos chilenos que había presos. La indignación que ha causado el acontecimiento de que me ocupo ha sido tan profunda... que no podría esplicarme cómo hasta ahora no ha habido una colisión entre nuestros nacionales y la fuerza armada" (Nota del cónsul Villegas, 29 de Mayo 1872, en Vicuña, 1880a: 26).

Los frecuentes abusos se tradujeron, según Vicuña, en que los chilenos comenzaran a practicar con maestría el culto popular al arma conocida como "cuchillo corvo". El elogio que sigue deja en evidencia que Vicuña selló esta particularidad tecnológica del roto chileno "del Norte", arma inscrita hasta ahora en la memoria "popular" militarizada como elemento característico de la chilenidad más cruda, degolladora:

"hizo su primera aparición el cuchillo corvo tan temido por el soldado indígena [boliviano]...El cuchillo corvo es solo conocido en las provincias del norte y especialmente entre los mineros de Atacama [Copiapó]. Consiste en una hoja pequeña ligeramente curva como los alfanjes moriscos y ofrece sobre el puñal recto la ventaja de la defensa, porque en las riñas obra en cierta manera como broquel para parar los golpes. Por su forma es de mucho más difícil manejo que la daga recta, usada por nuestros campesinos del sur, pero los mineros aprenden su esgrima especial que requiere mucha más flexibilidad en la muñeca que vigor en el brazo. Los bolivianos han tenido siempre un verdadero terror a este cuchillo; y de él hablan documentos oficiales tan antiguos como el descubrimiento de Caracoles" (Vicuña, 1880a: 27).

Ese mismo año tuvo lugar el escandaloso alzamiento de Quentín Quevedo, boliviano refugiado en Chile por melgarejista, quien con otros rebeldes embarcó en

la guerra del Pacífico fue nombrado delegado de Caracoles, donde desarrolló una planta amalgamadora, e Intendente de Antofagasta a partir de 1888, donde seguía en el puesto para la revolución de 1891, manteniéndose fiel a Balmaceda. Marchó a Santiago con las fuerzas a sus órdenes y se batió en Concón. Fue perseguido y hostilizado después de Placilla, pero en 1892 se trasladó nuevamente al norte y organizó el partido Liberal Democrático, que lo llevó al Congreso como senador por Antofagasta para el periodo 1897-1903, integrando la Comisión Permanente de Guerra y Marina. Entre 1906 y 1912 fue electo senador por Coquimbo, presidiendo dicha Comisión además de integrar la de Culto y Colonización. Fue ministro de Hacienda entre el 19 de noviembre de 1901 y el 6 de mayo de 1902; ministro de Industria y Obras Públicas, entre el $1^{\circ}$ de agosto de 1905 y el 6 de octubre del mismo año. Al terminar su mandato senatorial en 1912, se alejó de las tareas políticas y se radicó en Viña del Mar. 
Valparaíso, para intentar luego, desde Cobija, una revolución que les diera el gobierno de La Paz. Quevedo recibió apoyo de algunos miembros del gobierno chileno que proponían una alianza guerrera en contra del Perú para redibujar los límites sudamericanos y Chile hacerse del litoral de Atacama, dejándole a Bolivia su "puerto natural" de Arica (Paz Soldán,1884, 779-784). Quevedo luego diría haber quedado muy afectado por este ofrecimiento: fue tal vez por esto que su extravagante asonada se desinfló y fracasó sin un tiro, en Tocopilla.

Vicuña Mackenna deja en claro que bajo los presidentes bolivianos Ballivián y Frías (entre 1873 y 1876), hubo una suerte de tregua en lo que él llama "rencores de raza", latentes en el Litoral, calmándose algo las pasiones durante la prefectura del doctor Emilio Fernández Costa. El progreso material y asociativo fue notable. En 1873 se construyó la cárcel de Caracoles, que tuvo su Intendente de Policía, 2 comisarios, 2 cabos celadores, más 12 celadores a pie y 6 montados. Con todo, las revueltas y revoluciones eran frecuentes: el 13 de Febrero de 1874, el Coronel Miguel Santa Cruz encabezó una revuelta con unos 60 adeptos, en su mayoría chilenos. Tras irrumpir en el cuartel de Caracoles, toma prisionero a las autoridades y proclama como jefe supremo a Jorge Oblitas (que posteriormente formaría parte del gobierno de Daza). Pero el rebelde es apresado en su marcha sobre el puerto, cerca de Punta Negra, por tropas que habían salido de Antofagasta para combatirlo. La miserable montonera chilena bajo su mando se dispersó, algunos de ellos saqueando Calama. El subprefecto de esa ciudad informa a su par de Caracoles, Exequiel Apodaca:

"ayer a las doce poco más o menos, ha sido vatida [sic] la cuadrilla de chilenos ladrones, saqueadores y cobardes alevosos que en alta noche asaltaron este puesto en el numero de 30 chilenos venidos del mineral de Caracoles los que han sido escarmentados después de diez minutos de un combate en los suburbios de este pueblo [Calama], por dieciséis valientes bolivianos, quedando seis muertos y ocho prisioneros" (Bravo, 2008: 35).

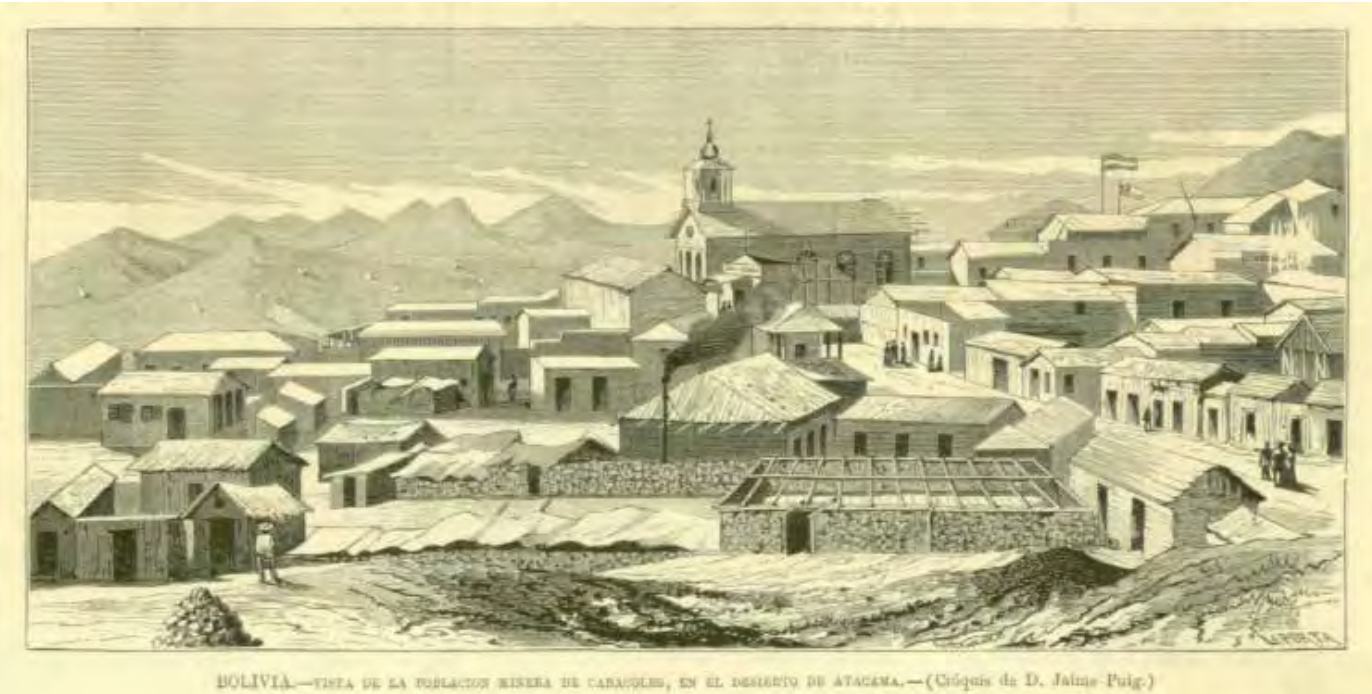

BOLIVIA - Vista de la población minera de Caracoles, en el Desierto de Atacama. "La Ilustración española y americana - Año XVIII. Núm. 44. Madrid, 30 de noviembre de 1874" (nótese la presencia de una bandera boliviana y de otra, chilena, en el fondo). 
Rumbo nuevamente a Calama para ser puesto en prisión, Santa Cruz intenta suicidarse. Apuñalándose en el camino, fallece de sus heridas en el traslado a Antofagasta dos días después.

El cementerio laico de Caracoles se construyó finamente tras algunos roces ideológicos locales, en Febrero de 1874 (González, 2005). En la ciudad se publicaban El Eco de Caracoles, La Flor del Desierto, El Globo y La Patria (fundado por Ladislao Cabrera, el mismo que organizaría la defensa boliviana de Calama). La construcción institucional del desierto tampoco escapó a las divisiones de género: a la escuela de niñas se le llamó María Josefa Mujía, y fue fundada el 6 de agosto siguiente (día de Bolivia) en honor a la poetisa boliviana, e inaugurada junto a la parroquia por el cura de San Pedro de Atacama, el Dr. Segovia.

La escuela de niños José Victorino Lastarria, se fundó poco después, el 18 de Septiembre, día de Chile. Este tipo de acomodos simbólicos era común: La vida regional era bullente e integrada pero las diferencias eran cada vez más marcadas, al son trepidante de la prensa ditirámbica que incendiaba la joven opinión pública regional.

Convertida en ciudad, Caracoles hacía gala de todas las virtudes de civilización que pudieran caber en tamaño campamento minero, y de toda la miseria e incertidumbre que proliferaba en los suburbios. El 6 de Agosto del año 1875, se inauguró el edificio de la subprefectura y se congregó una junta municipal de 5 miembros. Cuando un incendio redujo a cenizas la mayor parte de la población el 8 de Agosto de 1876, centenares quedaron en la indigencia.

Tanto Vicuña Mackenna como Barros Arana y Encina sostienen que el sistema de las extorsiones y del flagelo, de la penca y del rifle se hizo habitual como parte del pésimo ejer-

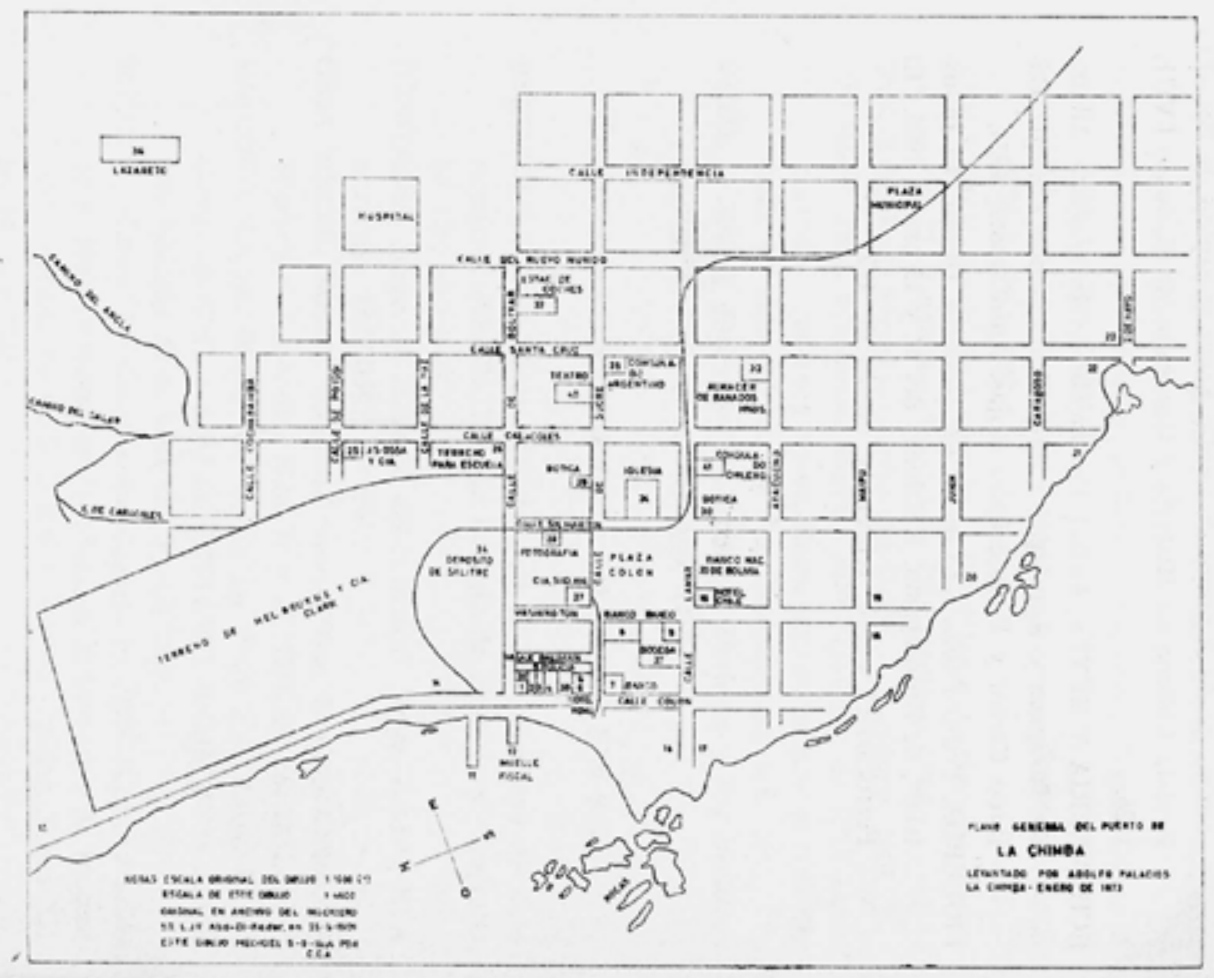

Plano del puerto de La Chimba. 1873.

Fig. 2 Plano general del puerto de La Chimba - 1873 (en Bermudez 1966) 
cicio público de la justicia bajo el gobierno de Daza, a partir de 1876. Uno de sus primeros actos administrativos fue nombrar juez de letras de Caracoles -donde se ventilaban grandes valores- a Bartolomé Rebollo, que según constaba de los libros del juzgado del crimen de Cobija, tenía un par de acusaciones penales a cuestas, una por lesiones e intento de asesinato en contra de Sebastian López, en 1874, y otro cargo por robo de dinero y especies al doctor Manuel María Berazaín, en 1875 (que había sido juez de letras en San Pedro de Atacama, Vd. Barros, 2008a). Aunque semejantes acusaciones fueron probablemente montajes judiciales entre rivales políticos, reafirman el aura de venalidad que rodeaba a las autoridades bolivianas, especialmente bajo las dictaduras de Melgarejo y Daza.

Corría el año 1876 cuando, en Caracoles, se funda la sociedad de socorro mutuo $\mathrm{La} \mathrm{Pa}$ tria, aparentemente dirigida a la unión y auxilio de los chilenos bajo un solo cuerpo directivo. Se participaba en ella mediante una suscripción mensual, y el compromiso de someter a arbitraje toda cuestión litigiosa que sobreviniera entre sus miembros (Ver Anexo 3). En el fondo, sin embargo, la organización tenía en vista "la emancipación política del Litoral de Bolivia", esto es, de todo el territorio ocupado por los chilenos al sur de la península de Mejillones. La junta directiva se instaló formalmente en Caracoles con asistencia de ochenta de sus socios fundadores, el domingo 12 de noviembre, en el vasto edificio de la que había sido la panadería Neves y Ca . Según Encina, La Patria llegó a congregar a 10 mil miembros, entre patrones y obreros; funcionaba como una suerte de logia lautarina:

"celebraba tenidas secretas; sus miembros se reconocían por signos, palabras y tocamientos; los iniciados prestaban juramento de rodillas, con la mano derecha sobre la bandera de Chile, de obedecer ciegamente los mandatos del jefe, en defensa de la Patria, de su honra y de sus intereses. El signo de reconocimiento consistía en colocar el dedo índice sobre el pulgar en forma de cruz; la pregunta se hacía con la mano derecha y se contestaba con la izquierda. La palabra sagrada era Patria, que no se daba sino en casos muy calificados y con solemnidad especial. Pero había una palabra de pase, de uso corriente entre los iniciados, adoptada no se sabe cómo ni en qué circunstancias, de entre los más vulgares motes de nuestro pueblo. Se daba en forma velada, con cualquiera de los versos del cuarteto: Por la $\mathrm{P}$, eres piurana; por la U, urubambeña; por la $\mathrm{T}$, trujillana y por la $\mathrm{A}$, arequipeña. En las disputas más agrias, en los bochinches más crudos, productos del alcohol, corría un verso, y como por encanto, llegaba la calma, el buen humor, la confraternidad de los hijos del mismo suelo, ligados por el misterioso lazo del amor patrio" (Machuca, 1926: 32).

El trasfondo masónico de La Patria y su rol permanecen en la sombra, pero sin duda está ligado a la acción asociativa que promovía el Partido Radical, especialmente en Copiapó (hoy Región de Atacama), cuya prensa se declaraba abiertamente en favor de la guerra, llamándola ${ }^{7}$. También se aprecia la común ramplonería denigratoria de la mujer como puta (peruana, en este caso), clave de pase al centro del secreto, que prefigurando de este modo la explosión machista de la guerra, se alineaba con la imaginería sexual de cuchillos corvos y yataganes. Imbuidos de fervor liberal-nacionalista, mítines y discursos inflamaban las facciones, instigándose reyertas locales de todo tipo, en abierto desacato de la autoridad boliviana -incluso internando armas en forma ilegal. Es entonces que el mando militar del Litoral escribe preocupado a La Paz:

7 Ortega y Rubio (2006) esbozan la parte que le cupo al Partido Radical en Atacama y Coquimbo durante la guerra civil de 1859. 
"[Hay en Caracoles] una asociación denominada La Patria cuya desembozada tendencia es la de erigir un Estado, una Patria con su gobierno y autoridades independientes, impuestas sobre el gobierno y autoridades de Bolivia" (Memoria del Ministerio de Relaciones Exteriores, 1877: 55) ${ }^{8}$.

Los bolivianos reaccionaron persiguiendo a los chilenos con una violencia incrementada: la noche del 19 de noviembre siguiente tuvo lugar otro incidente, al interior de una chingana en una fiesta de obreros chilenos borrachos y cantando. Un contingente de la policía boliviana abrió súbitamente fuego sobre los festejantes, y una bala perdida alcanzó a Eliseo Arriagada, chileno que no tenía nada que ver con la fiesta ni con los ebrios. Murió desangrado en el lugar.

Como tal vez nunca antes, la noticia provocó un sentimiento antiboliviano entre los "rotos", al punto de que, siguiendo con su relato nacionalizante, Vicuña (y luego Encina) describe una masa iracunda de unos cuatrocientos individuos avanzando hacia las autoridades bolivianas con intención de linchar, corvos y palos en mano. La justicia de los cuchillos corvos hubiera alcanzado su terrible cometido, de no haber el sub-prefecto boliviano acudido oportunamente a los notables chilenos de La Patria, como ya era costumbre en tales casos. Su influencia de amigos y patrones, solía deshacer los tumultos.

"En lo más serio del conflicto" informaría oficialmente Villegas, "los señores B. Navarrete, J. M. Walker, Francisco M. Oliveira, Marcos Lathan con el sub prefecto, que los buscó expresamente, se fueron al teatro de los acontecimientos y lograron, después de mucho trabajo, y aun exponiendo sus vidas, apaciguar a la muchedumbre que en estos momentos estaba exasperada a la vista del cadáver de su compañero, pidiendo a gritos lanzarse sobre el cuartel de policía donde se encontraba el autor del asesinato" (Vicuña, 1880a: 29. Carta de Villegas, 20 de noviembre de 1876).

Al día siguiente, la policía permaneció encerrada en los cuarteles mientras duró el funeral de Arriagada. Tras la vigorosa y airada protesta de Villegas, los bolivianos esta vez culpan a La Moneda del alzamiento, denunciándolo como una conspiración azuzada desde Chile por intermedio de La Patria. La acusación culmina con el retiro del exequátur a Villegas y una nueva oleada represiva. El destacamento al mando de Juan Granier que llega desde Antofagasta para reprimir los posibles desórdenes, comienza inmediatamente a ejercer acciones contra La Patria, acusada de incitar los alzamientos.

Al formarse el nuevo padrón electoral del flamante municipio de Caracoles, quedó nuevamente expuesta la gobernabilidad del territorio: la mayoría cabildante era chilena, y la autoridad policial y militar, boliviana. El gobierno boliviano deseaba a toda costa evitar el surgimiento de otra institución compuesta por una mayoría chilena que, como el cabildo de Antofagasta, representaba los intereses nacionales a la vez de encubrir afanes independentistas. Las autoridades bolivianas se las arreglaron para impugnar y rechazar la inscripción de más de 100 chilenos en el registro municipal caracolino. El 24 de noviembre, el prefecto Granier le escribe a Claudio Acosta, Comandante de Armas de La Chimba (Antofagasta):

\footnotetext{
8 A fines de 1876, la sub prefectura de Caracoles era desempeñada por el coronel don Exequiel Apodaca, natural de Tarija, que no era demasiado duro con la población chilena, con excepción del manejo de sus negocios personales en que era juez y parte. El Caracolino del $1^{\circ}$ de febrero de 1877 establece que siendo propietario de cuatro barras de la mina Altamira, Apodaca mandó embargar los metales que en ella había explotado el ciudadano chileno don Juan Agustín Palazuelos (miembro fundador de La Patria), interponiendo para el caso su tercería de minero junto con su poder de sub prefecto. Apodaca desempeñó luego el puesto de Jefe de Estado Mayor de la $5^{\text {a }}$ División boliviana, bajo el mando del general Campero.
} 
"Existen tendencias de nuevos desórdenes con motivo de la excitación eleccionaria del municipio y algunos tenaces azuzadores de la rotería en días de pago, cuando todos los mineros se hallan reunidos en esta población” (citado en Vicuña, 1880a: 21).

El prefecto ordena citar a los colonos más activos para que se apersonen a explicar, en Antofagasta, el origen y tendencia de La Patria y dar cuenta del programa publicado por la sociedad el 19 de octubre anterior (Vd. Anexo 3), notificando el sub-prefecto de Caracoles a Juan Palazuelos y Luis Lichtenstein (este último, un alemán dueño de una empresa de carretas) ambos sindicados como autores y promotores. Siempre según Vicuña y las mismas memorias de Relaciones Exteriores, el año 1877 fue particularmente grave para los chilenos. El látigo, instrumento penal boliviano, ultimó a un chileno en Tocopilla. Los bolivianos más informados no ocultaban su preocupación ante el rumbo autonomista tomado por $L a$ Patria bajo el alero del "socorro mutuo":

"La Sociedad La Patria, si tiene los nobles y santos propósitos de socorrer al pobre y desvalido, también tiene otro que es su fin primordial. Ella tiende a establecer entre sus asociados, que son todos los chilenos del Litoral, es decir, toda la masa pobladora de esa región, la obligación de dirimir toda cuestión judicial por medio de árbitros, dejando a un lado la justicia del país. Creo que va aun más lejos. Creo que los asociados se comprometen a someterse a un tribunal fijo, nombrado por la Sociedad. La constitución de esa Sociedad es positivamente la formación de un Estado boliviano al cual le arrebata una prerrogativa que le es propia. Ella usurpa al país en que se ha formado, donde sus miembros reciben hospitalidad y en el cual quizás van a hallar fortuna, la administración de justicia, facultad que se desprende de la soberanía" (Carta del ciudadano boliviano don Luis Salinas Gómez al redactor de El Ferrocarril don Justo Arteaga Alemparte, fecha 24 de enero de 1877, publicada en El Deber del 2 de febrero de ese año, en Vicuña, 1880: 33).

Vicuña describe minuciosa y explícitamente los planes urdidos en el seno de la organización, patriótica y revolucionaria. En palabras de Villegas:

"sus principales miembros, no desmayaban en la patriótica tarea que se habían impuesto, y sus trabajos i esfuerzos se concretaron a la Independencia del Litoral, cuya prosperidad y desarrollo se debía y se debe exclusivamente al trabajo de los chilenos; por consiguiente nos pertenecía de hecho y de derecho" (énfasis original) (Vicuña, 1880a: 57).

Para ocultar en parte su verdadero propósito, La Patria nombró a un caudillo boliviano para que, incautamente, éste fuera quien hiciera de cabeza del movimiento revolucionario chileno, enarbolando la bandera de la independencia federalista en contra de Daza como señuelo. Según Villegas, esta estratagema:

"fue buscado exprofeso para hacer menos sospechoso el verdadero carácter de la revolución. Todo se consiguió y se llevó a feliz término... porque el caudillo federal boliviano se puso de acuerdo con ciertos individuos prestigiosos de su país, individuos que hoy mismo son personalidades en las altas regiones de la política y gobierno boliviano" (Vicuña, 1880a: 37). 
No es de extrañar que, informado y consultado Hilarión Daza en La Paz, éste ordenara al Prefecto Granier que, en cuanto a La Patria se tomen:

"las más eficaces providencias siempre que sus miembros, apartándose del objeto de su asociación, sigan con las malas tendencias que han principiado a manifestar, sometiéndolos a un juicio breve y severo, o bien, en caso urgente, espulsándolos fuera del territorio, ya que por su parte se atribuyen un poder que cede en desprestigio de la ley y de las autoridades encargadas de su cumplimiento. [...] Los tumultos y desórdenes que vuelvan a poner en conflicto a los laboriosos industriales, deben ser reprimidos con toda oportunidad y energía, y en este concepto, aguarda el gobierno que con la sagacidad y tino que caracterizan a Ud., restablecerá por completo la moralidad relajada por instigaciones de los que, por su posición social y por su propio interés, debieran observar una conducta circunspecta. [...] Un escarmiento oportuno que se haga principalmente con los cabecillas y promotores de esos hechos, será suficiente a contener a la peonada desbordada e inobediente, sobre cuya conducta la acción represiva y policial debe ser instantánea e infatigable. [...] Quedando Ud. autorizado plenamente para obrar contra los contraventores a las leyes del país, de la manera más eficaz y oportuna [etc.] (Impreso en E1 Caracolino del 10 de enero de 1877, en Vicuña ,1880a: 40).

Bolivia tenía buenas razones para temer una revolución social chilena, pero la idea de instaurar un nuevo Estado independiente en el litoral también se instalaba con fuerza entre la elite chilena, como una posibilidad al alcance de la mano. Los agentes de La Patria no desmayaban:

"En Valparaíso se recopilaron todos los elementos del caso; allí se formuló la constitución para el nuevo Estado (el cual según dicho documento debía ser regido interinamente por un Triunvirato); se compraron armas; magníficos rifles de precisión, revólveres, sables, etc., etc. Para hacer frente a los gastos que originaban todos estos aprestos, se buscaron los fondos necesarios y se firmaron bonos al portador por una suma no indiferente y por el caudillo adhoc. Todos los documentos a que se hace referencia, constitución, bonos, etc., etc., no pueden ver la luz pública por el momento; pero en poco tiempo más desaparecerá este inconveniente" (Vicuña, 1880a, 37).

Las armas compradas por La Patria en Valparaíso fueron ocultadas en sacos de cebada y fardos de pasto, y embarcadas en el paquete Los Vilos que partió el día 22 de marzo de 1877, llegando a Antofagasta el día 24, donde se supone debían ser desembarcadas dos días después. Pero el plan fracasó porque el mismo día del desembarque previsto, llegó al puerto la noticia de que el Coronel Rufino Carrasco se había levantado en armas e iniciado una revolución en apoyo del entonces caudillo nacional indígena, el Dr. Casimiro Corral. El guerrillero salió del oasis de Quillagua (entonces limítrofe de Perú y Bolivia) en dirección a Caracoles, saliendo el sub-prefecto Apodaca de la ciudad a su encuentro. Tras un enfrentamiento con muertos en ambos bandos, Apodaca siguió rumbo hasta Antofagasta, y Carrasco se toma Caracoles.

Mientras, en Antofagasta, uno de los bolivianos comprometidos con La Patria ("más por felonía que por amor a su patria" dice Vicuña Mackenna), denuncia la existencia de las armas ilegales al prefecto Granier quien se apodera de ellas y se dirige inmediatamente al mineral con su tropa, plegándosele la de Apodaca con la que se encuentra. En Caracoles, Granier trata de forzar, con algunos soldados, la puerta del edificio de la subprefectura en 
que se había parapetado Carrasco. Las hostilidades se suspenden tras la descarga que recibe Granier en la mano; interviniendo, el cónsul italiano le pide a Carrasco hacer abandono de la ciudad para evitarle peligros a la población civil. Accede el Coronel, y tras acampar en el cerro, es derrotado por el general Acosta en la mañana del día 30 de marzo. Enterada Antofagasta de los hechos el 2 abril, se echan al vuelo las campanas, y el puerto se entrega al regocijo.

"Las autoridades, sin medir las consecuencias, ordenaron que se repartiera entre la población algunos barriles de vino, pero éstos se agotaron y el pueblo enardecido por los efectos del licor, exigió que se les entregase más, a lo que las autoridades y comerciantes se negaron rotundamente. Pero como el número de ebrios era ya crecido, algunos más exaltados, se propusieron derribar las puertas de varios negocios que existían en la calle Lamar [hoy Prat] entre las de Caracoles y Santa Cruz, a fin de continuar sus libaciones" (Arce, 1930, 259).

Las autoridades bolivianas decidieron dispersar la población haciendo uso de sus armas, de lo que resultaron dos muertos -uno argentino el otro chileno- y varios heridos. Los cónsules respectivos emitieron enérgicas protestas al Prefecto, quien lamentó el incidente, justificándolo.

"Y aunque esta noche era viernes santo... se echaron las campanas al vuelo en Antofagasta y la autoridad hizo dar licor sin tasa ni medida a la muchedumbre que se reunía en la plaza, y esto, como es natural, produjo los mayores desórdenes. Con tal motivo y para sofocar esta nueva revolución producida por la misma autoridad y tal vez premeditadamente, se mandó fuerza armada a las calles y con orden de hacer fuego sobre la gente tumultuosa, orden que fue cumplida al pie de la letra, resultando seis ciudadanos chilenos heridos, de más o menos gravedad, y un argentino. [...] Aquella noche fue aciaga, tremenda para Antofagasta y lo que más cólera nos daba, a los que presenciábamos aquellos sucesos, era el saber que las armas que habían venido para defendernos y defender a nuestros connacionales estaban sirviendo para ultimarlos" (Villegas citado en Vicuña, 1880, 37).

El abuso contra los chilenos transmutó "en un profundo odio antiboliviano y antiperuano en lo más oscuro del alma de los miles de "rotos" dispersos por Atacama y Tarapacá" (Ibid.) $)^{9}$ Según esta versión, tal odio fue obra de los agentes policiales que estigmatizaban a los "rotos" mediante su constante humillación, tratando metonímicamente a estos mestizos empobrecidos, como a bárbaros Indios, horda araucana sedienta de sangre y ávida de rapiña, imagen del Indio vehiculada tempranamente por la prensa de cada uno de los beligerantes ${ }^{10}$. Una mayoría excitable de chilenos se sentía, indudablemente, oprimida y desprotegida ante el abuso constante reseñado y ampliado por la prensa, terribles noticias que se expandían con alarma, alimentadas por la angustia producida por las continuas e incesantes amenazas bolivianas de cerrar la CSFA, clausurar el puerto y expulsar a los obreros chilenos del territorio, como había ocurrido en el Perú. El 26 de enero de 1877, el editorial de El Atacama, un diario copiapino, interpela a Pinto y al ministro Alfonso para que actúen enérgicamente:

9 Las autoridades bolivianas, en particular las policiales, se habían ganado el encono de la población chilena, que según diversos autores, no olvidaría la 'aciaga noche del 31 de marzo de 1877 [2 de abril según Arce], el fusilamiento en masa del Pueblo de Antofagasta' (Ibid.)

10 El ejército chileno repetidamente hizo valer con bizarro orgullo las tácticas indígenas empleadas en la Araucanía, incluyendo tácticas marciales mapuches, como el chivateo y la razzia o malón. 
“SSabe [el ministro de Relaciones Exteriores José Alfonso] cual es la verdadera situación de los chilenos en Caracoles? ¿Ignora por ventura que el sub prefecto de Caracoles, la primera autoridad de ese mineral, es propietario de minas? ¿Ignora el señor ministro que jueces instructores ha tenido el mineral que han llegado a ese puesto después de haber sufrido condenas ante el tribunal superior de Cobija por robo y asesinato? Y cuando tales cosas se ven en ese desgraciado país ¿es lógica la conducta del gabinete chileno? ¿Por qué el señor ministro ha guardado ante el país indignado un silencio culpable? ¿Por qué no ha dado a luz siquiera las notas del cónsul de Chile, señor E. Villegas, dándole cuenta de los sucesos, como asimismo de las contestaciones del ministerio? El país tiene derecho a pedir al hombre colocado en el elevado puesto del señor Alfonso, energía y justicia. Tiene derecho a esperar que no sea vejada la dignidad nacional, y que ministros charivarescos de un gobierno de carnaval no hagan irrisión de un representante de Chile en el extranjero. La política de tolerarlo todo y de sufrirlo todo, de quien quiera que sea, no es política de un país como el nuestro que ocupa un alto puesto entre las naciones sud americanas" (Vicuña. 1880, 43).

Luego vinieron el poco recordado terremoto de grado 9 y posterior maremoto de 9 de mayo de 1877, que arrasó el litoral boliviano, y cuya acción destructora fuera rematada por otro fuerte sacudimiento en enero de 1878. Cobija, Tocopilla y Mejillones y toda la infraestructura del litoral desapareció completamente, en Chiu-Chiu y Quillagua nada quedó en pie, salvo Antofagasta que, acurrucada en la bahía sur de la península de Mejillones, quedo protegida del embate mayor de la ola, gigante, con dirección norte sur. Fuertes oleadas se sintieron en lugares tan distantes como Hawái, las Islas Marquesas, México y California (Barros. 2011). En el congreso boliviano, los diputados por la zona propusieron cobrar un impuesto adicional de 10 centavos a la CSFA, justamente como forma extraordinaria de recaudar fondos para reconstruir el litoral devastado, y así no recurrir a un empréstito ¿cómo imaginar que esos diez centavos desencadenarían una guerra?

Los febriles preparativos revolucionarios de La Patria quedaron en suspenso y algo acallaron los bullicios populares y alardes guerreros pro-chilenos, pues ¿qué objeto tenía apoderarse del montón apelmazado de ruinas humeantes que dejó el maremoto? Solo Antofagasta quedó parcialmente en pie, protegida por la península de Mejillones, cuya asa norte, la ancha Bahía de Algodones y el pueblo de San Luciano, recibieron lo peor de la furia marina, junto con Cobija y Tocopilla. Cualquier acción revolucionaria se hizo impensable: la dotación del Blanco Encalada, surto en el puerto al amparo del Morro Moreno, apoyó solidariamente la reconstrucción, incluso, reforzando las labores de policía.

Por esas mismas fechas, el diputado Ángel Custodio Vicuña exhibía en Copiapó y Santiago una herramienta atribuida a algún ingenioso policía de la costa, conocida como "penca" (del cactus), hecha con restos de materiales usualmente utilizados en las calicheras y estaciones: varias tiras de alambres trenzados con una bola de fierro, tuercas o una cabeza metálica en sus extremos. Según Vicuña, cualquier excusa bastaba: una palabrota, una mala mirada o una muestra cualquiera de rebeldía de parte del chileno podía acarrear la muerte. La prensa chilena de la época informó de varios casos donde el uso de este instrumento había culminado en la muerte del torturado, a lo que la prensa boliviana local contestaba:

"Aquí no hay tal "penca" y si más bien cuchillos corvos que nos han traído algunos paisanos del cónsul Zenteno" (Editorial de El Caracolino, octubre 17 de 1877). 
Sin perjuicio de los desmentidos bolivianos, otra ola de indignación chilena inundó la noche antofagastina el 13 de noviembre de 1877, cuando fue asesinado a sablazos el chileno Benito Berríos por dos policías.

Así, vemos como los conflictos sociales no dieron tregua: recaían sobre estacas mineras, asuntos de faldas, alcohol, juego, cuatrerismo y una infinidad de causas más... Era el "Far-North" o Norte Grande chileno en ciernes, una "calichefornia" criolla imaginada como frontera de colonización, riqueza y condiciones extremas, bajo el débil, legítimo, aunque no menos despótico yugo de La Paz. Latía la tentación de las armas. Con Bravo, observamos que los fenómenos de violencia, el bandidaje, y las riñas callejeras también iban en aumento durante el período, entre chilenos: la temible fama de asaltantes de caminos como "El Chichero" y "El Colorado" reflejaba la guerra social en ciernes. Es razonable concluir parcialmente que el hambre, junto al desempleo y la migración masiva, fueron los verdaderos precursores regionales de la guerra internacional.

La situación empeoró con el incremento de cientos de obreros más que bajaron de Tarapacá ante las difíciles condiciones de trabajo y desempleo que siguieron a los torpes intentos del gobierno peruano por monopolizar la comercialización del salitre. Los chilenos que se establecían en Antofagasta por aquellos años no provinieron solamente del Sur, sino que desde Perú, donde los rencores nacionalistas ganaban asimismo terreno, y los chilenos eran tratados con desdén, como "rotos".

El envenenamiento diplomático y militar del ambiente internacional, especialmente entre Argentina y Chile, reforzaba localmente el trato brutal boliviano contra la creciente "masa" chilena y extranjera, completamente dependiente de la floreciente industria salitrera: en Mejillones, fue noticia la azotaina que recibió el chileno Juan Navarro por ebriedad. Al parecer, muchos chilenos de Cobija, Tocopilla y Mejillones eran encarcelados o castigados sólo por no portar sus papeletas de nacionalidad.

El muro local de incomunicación entre policía bolivianos y masa chilena se tradujo en un sentimiento de mutua desconfianza con ribetes cada vez más racializados y xenofóbicos, los mismos que empresarios y políticos regionalistas y nacionalistas como Villegas, radicalizaban y ahondaba por medio de la prensa, mítines y arengas, endureciendo las diferencias con los bolivianos, todos, por lo demás, azuzados por la CSFA y La Patria.

La prensa populista de La Serena, Copiapó, Valparaíso llamaba activamente la intervención militar chilena para sacar tanto el salitre como a la gente, del odiado dominio boliviano, aunque claramente, la prensa más conservadora también contemplaba la posibilidad bélica como forma de frenar de una vez por todas también las renovadas ambiciones monopólicas y hegemónicas peruanas. Algunos industriales y comerciantes chilenos y extranjeros residentes en Antofagasta y Caracoles, unidos a la CSFA, informaban secreta y efectivamente a las autoridades de Santiago. Vicuña resume afrancesada pero no menos ajustadamente, el zeitgeist de lo que vino (y no era precisamente con espíritu teutón).

"Faltaba solo la oportunidad de las armas, y ésta fue la que llevó a Antofagasta en febrero de 1879 el coronel Sotomayor, este nuevo Frémont de las conquistas de la civilización en tierra americana" (1880a: 23) ${ }^{11}$.

De nuevo la metáfora californiana...

11 John Charles Frémont (1813-1890) fue un explorador y general estadunidense, conocido como forjador de la independencia de California frente a México. Buen número de los oficiales chilenos hicieron sus estudios y recibieron sus diplomas en las escuelas militares de Lieja, Saint-Cyr, Metz y la Politécnica de Paris (y no en Prusia, como se suele confundir). Las tropas se organizaron también finalmente, según el modelo militar británico, incluyendo la así llamada guerrilla inglesa, que avanzaba con forma de rombos, no de cuadros (Machuca 1926, 138 y ss, 263). 


\section{Especulaciones salitreras y argentíferas: la Compañía de Salitres y Ferrocarriles de Antofagasta y el mineral de Caracoles}

Los 10 centavos fueron el catalizador simbólico de esta guerra que venía desplegando sus mortíferas redes hace décadas. Tuvo claros antecedentes discursivos, económicos, intelectuales y geopolíticos arraigados en la guerra contra la Confederación Perú-Boliviana del Mariscal Andrés de Santa Cruz y Calahumana (Barros, 2009).

Congratulándose de la humillación que los medios de prensa internacionales infligían al gobierno chileno a consecuencia del retiro que hizo el Presidente Pinto, de las pretensiones sobre la Patagonia oriental (disputada y reclamada por Argentina como propia), Daza pensó que, por lo pronto, Chile no reaccionaría a su meditada provocación tributaria en apoyo del Perú $^{12}$. El dictador boliviano quería frenar la expansión anglo-chilena para re-concesionar o arrendar el salitre atacameño en beneficio del Perú. Además de 'fregar a los gringos', aspiraba conseguir dinero fresco para su propósito militarista, por lo demás declaradamente anti-chileno - confederado con el Perú ${ }^{13}$ (Vid. Anexo 2).

Los párrafos que anteceden, igual que los que siguen, muestran cómo fueron encajando algunos engranajes sociales de la guerra, eventualidad cada vez más inexorable en consideración a las riquezas inmediatamente en juego y las crisis internas de cada beligerante (Ortega 1984). Caracoles estuvo al centro de las disputas limítrofes y fue un objetivo primordial de la campaña: de Antofagasta, las tropas chilenas fueron casi inmediatamente al mineral, aprovechando el tren y las carretas. Los 'diez centavos' bolivianos no eran solo una forma de obtener recursos para la reconstrucción del Litoral, como planteaban los diputados electos por la zona. Tal como lo han demostrado Crozier y Ravest, los 'diez centavos' fueron exigidos por Bolivia a instancias del Perú y de la misma Gibbs y Co. encarnando así la peor irracionalidad especulativa del capitalismo desatado, el cartel fomentaba el impuesto adicional desde sus oficinas de Lima (para consolidar su posición monopólica), a la vez que desde sus oficinas de la CSFA en Valparaíso, se ufanaba de poder gatillar la guerra de proseguir Bolivia con el cobro del mismo:

"tenemos a varios chilenos muy influyentes entre nuestros accionistas y si el Gobierno no cumple su promesa de tomar acción inmediata en el asunto, se ejercerá fuerte presión sobre ellos en el Congreso y sin duda se verán obligados a actuar y a actuar con energía" 14 .

Según manifestara luego uno de estos miembros de la Casa Gibbs a su matriz en Londres:

12 Anotamos que Arturo Prat regresó a Chile el día 16 de Febrero de 1879, dos días después del desembarco en Antofagasta, tras culminar su misión como agente confidencial chileno en Montevideo, desde donde informaba en detalle sobre los preparativos de guerra de Argentina, recomendando incluso, aprestos comparables por parte de Chile (Barros, J. M., 2008). En efecto, pocos meses antes de iniciarse las hostilidades contra Bolivia, hubo un grave incidente limítrofe con Argentina, conjurado por el gobierno de Pinto a finales del año 1878 y finiquitado con el tratado Fierro-Sarratea de 14 de enero de 1878 (González 2005, 355). La resolución del incidente disminuyó las posibilidades electorales del gobierno chileno de cara a las próximas elecciones parlamentarias: de no haberse declarado la guerra, el gobierno probablemente no hubiera seguido en el poder. La crisis económica era desastrosa (Ortega 2006, Sater 2007, 39 y ss). Como me confiara un oficial archivero militar: surgió un inexplicable espíritu guerrero.

13 A pesar del tratado defensivo suscrito en 1873, Perú y Bolivia tuvieron roces fronterizos en la zona del Toco: Perú sostenía que sus límites por el Sur no llegaban hasta el Río Loa, como decía Bolivia, sino que hasta Tocopilla, cerca de donde sus 'verdaderos fundadores', los hermanos franceses Maxime y Domingo Latrille, tras años de explotar las covaderas, habían hallado y obtenido concesiones sobre ricos depósitos nitrosos en el sector de El Toco (Cruz 1966, 36; Paz Soldán 1879).

14 Archivo Gibbs MS 11470/2, W. Gibbs and Co. a A. Gibbs \& Sons, 26 de marzo de 1878, citado en Mayo 1979,86 
'Los Directores [de la CSFA] están plenamente conscientes del hecho que su negativa a colaborar en llevar adelante el monopolio peruano puede atraerles la hostilidad del Gobierno, y nosotros pensamos que, hasta cierto punto, ellos atribuyen a intrigas del Gobierno del Perú el último atentado del Gobierno boliviano de imponer un gravamen de exportación de 10 centavos por quintal. Pero aparentemente sienten que esos, o similares atentados, no se llevarán a efecto en la medida en que puedan contar con el cordial apoyo del Gobierno chileno, con cuyo respaldo están muy seguros de contar a través del partido de Edwards (el Nacional o montt-varista). Por tanto, al no temer esa posible hostilidad no están llanos a variar sus tácticas’ (citado en Ravest, 2008: 77).

En la nómina de los accionistas de la CSFA, figuran hombres decisivos en la guerra, como Agustín Edwards Ross (actuaba como director, personalmente y en representación de la sucesión de su padre), Cornelio Saavedra (Ministro de Guerra), Alejandro Fierro (Ministro de Relaciones Exteriores, vendió antes de la guerra), Francisco Vergara (Ministro del Interior 1881-2, tenía acciones desde 1875), Rafael Sotomayor (Ministro de Guerra), José Eugenio Vergara, Antonio Varas (Jefe del $2^{\circ}$ Gabinete de la Guerra) o Miguel Varas y Julio Zegers (Ministro de Justicia). Muchos de ellos fueron además miembros pasados, presentes o futuros del congreso (Querejazu, 1979, Mayo 1979, 87; López, 1980[1933], 71; Ortega, 1984). El gran conocedor del Norte y magnate minero, Agustín Edwards Ossandón, fue controlador de la CFSA hasta su muerte, a inicios de 1878. Hereda su hijo, que había salvado al decano de la prensa chilena, El Mercurio, de la quiebra, el año precedente.

Tanto estos capitales, como aquellos ligados al Perú (entre ellos, los de la Casa Gibbs y de la Casa Dreyfuss, que corrían "a dos caballos") temblaban a la espera de asegurar su posición financiera en Tarapacá y Atacama (la que, luego de la guerra, monopolizaría Thomas North). La miríada de trabajadores y chilenos que formaba la opinión pública del desierto, seguía con preocupación la evolución del mercado mundial del salitre, y el giro que tomaban los acontecimientos internacionales detallados por las prensas regionales ( $\mathrm{p}$. ej. El Copiapino).

Se debe subrayar que George Hicks, el gerente inglés de la CSFA en Antofagasta, Las Salinas y Carmen Alto, fue el más ferviente opositor al cobro de impuestos por Bolivia, negándose incluso, y amparándose en el tratado, a pagar al municipio de Antofagasta una contribución por el alumbrado público (y a pesar de ser chilenos los munícipes del Puerto). Impulsor de la guerra y agente provocador, estaba abiertamente comprometido con los militares y la chilenización del Litoral boliviano, como forma de luchar contra el monopolio salitrero peruano, pero también, imbuido de un furor civilizador anti-boliviano.

El 31 de enero de 1879, es decir, dos semanas antes del desembarco de las tropas, el Cónsul chileno en Antofagasta, Nicanor Zenteno le escribe a Villegas para que le informe sobre el armamento boliviano que hubiere en la plaza de Caracoles. El ejército chileno evidentemente sostenía comunicaciones con La Patria y su fallida acción desestabilizadora de marzo de 1877 (vid. supra). Hicks estaba plenamente enterado de la invasión que se preparaba a rajatabla en Santiago. Conforme a sus órdenes, Villegas le entregó la información en Las Salinas:

"bien pudiera suceder que de Potosí viniera un batallón por esta vía, pues el año de 1872 ya vino uno compuesto de 280 hombres. Usted debe saber que estos malditos cuicos [apodo despectivo usado para referirse a los bolivianos], son mejores que las bestias para viajar el desierto... En Caracoles hay 12 a 14 rifles y en Calama y Atacama debe haber 10 buenos rifles" (Ahumada, 1885: 119-120). 
En la misma nota, el excónsul exhorta a 'dejar de ser extranjeros en nuestro propio suelo' $\mathrm{y}$, de modo algo contradictorio, a 'proceder inmediatamente a chilenizar el territorio' ${ }^{15}$. Tal vez sea ésta la primera vez que aparece la noción y voluntad de "chilenizar" tan claramente en los documentos que antecedieron la guerra. Este llamado de Villegas tuvo eco, porque el día 12 de febrero, el Ministro de Relaciones Exteriores chileno, Alejandro Fierro le anunció al ministro de Perú, Pedro Paz-Soldán, la inminente toma de Antofagasta. Éste ofrece los buenos oficios de su país para evitar tal fatalidad, a lo que Fierro habría contestado:

"con cualquier otro país que no fuera Bolivia... se apresuraría a acceder, [pero] el Gobierno de esa república se estaba burlando... que Bolivia quería ganar tiempo; que los chilenos del litoral estaban ardiendo, por sublevarse, y que por todos estos motivos no había más remedio que proceder a la ocupación" (López ,1980: 79-80, énfasis agregado).

En efecto, la situación en Antofagasta era crítica:

"todos se preguntan qué sucederá una vez efectuado el remate, al quedar cesantes 2.000 trabajadores y 300 empleados de la Compañía" (Machuca, 1926: 36)

El día 4, los notables de Antofagasta se enteraron que el prefecto boliviano, Severino Zapata, había recibido un cable de Mollendo (Perú) por el vapor que venía del norte, autorizándolo a tomar medidas violentas en caso de que la población se opusiera al remate (no existía telégrafo en Antofagasta, pero sí en Iquique). El 5 fondeó el vapor Limarí, que fue tramitado y despachado rápidamente por los bolivianos, sin dar tiempo para que los papeles fueran legalizados por el consulado chileno, por lo que no se pudo enviar la correspondencia oficial al sur e informar a Santiago del inminente ataque boliviano. Las autoridades bolivianas despacharon con igual rapidez el vapor Ayacucho, con rumbo al norte. Solo tras zarpar dicha nave, a las 4 de la tarde, la prefectura boliviana le notificó formalmente a la CSFA el remate de sus propiedades a efectuarse el día 14, previa tasación de los bienes embargados. George Hicks, con gran astucia, envió un 'propio' o mensajero a Mejillones a caballo, que a revienta cinchas alcanzó el barco, enviándose así luego oportunamente un cable a Valparaíso, vía Iquique. El día 9, Cornelio Saavedra uno de los accionistas de la CSFA, nombra al Coronel Emilio Sotomayor 'Comandante en Jefe de las fuerzas de mar y tierra destacadas en las costas del Norte de la República y en el litoral Boliviano' (Ahumada, 1885: 3), siendo él mismo uno de los hermanos del Ministro de Guerra, Rafael Sotomayor, también accionista de la CFSA. Los intereses de todos los chilenos en el litoral estaban siendo amenazados por la temeraria arbitrariedad de Daza: inversiones, seguridades, dinero, pan y trabajo quedaron en vilo, situación que la elite chilena juzgaba intolerable y el pueblo, injusta, al punto de estar dispuestos a tomar las armas, como en definitiva lo hicieron, la elite y el pueblo obrero, sellando con su sangre un nuevo pacto nacional.

Por esos días, los colonos, militares y representantes diplomáticos chilenos en Antofagasta organizaron dos reuniones secretas. A la primera de ellas, en casa de Matías Rojas; asistieron el Cónsul chileno en Antofagasta, Nicanor Zenteno, Evaristo Soublette, secretario de la Compañía de Salitres; George Hicks, gerente de la misma; Salvador Reyes, excónsul, Juan E. López, comandante del Blanco Encalada, además del dueño de casa. Zenteno expuso así la situación: las autoridades bolivianas tenían la tropa lista en pie de guerra; se aseguraba que en breve llegaría un cuerpo de línea; y era un secreto a voces que el Presidente

15 La plaza de Caracoles había estado envuelta en una disputa limítrofe, por encontrarse prácticamente en la línea divisoria definida en el tratado de 1874. 
Daza había dado orden, en caso de resistencia, de incendiar la ciudad, y especialmente las propiedades de la CSFA.

Se acordó comisionar Villegas a Caracoles; a Hicks se le encomendó vigilancia de las vías férreas y telegráficas para impedir, incluso por la fuerza, el incendio de la ciudad, para lo cual se avisaría a las administraciones de Carmen Alto y Salar del Carmen, para que acudieran con toda su gente; y por último, en caso de que el pueblo y la CSFA no pudieran resistir, pedir auxilio al Blanco Encalada; de día, con banderolas y el silbato de la CSFA, y de noche por medio de voladores de luces. Hicks y Soublette quedaron encargados de las señales, y Zenteno, Reyes y Rojas, para ponerse a la cabeza del pueblo. El comandante López, una vez de regreso a bordo, envió un plan completo de señales y la correspondiente dotación de banderolas y cohetes. Se guardó un secreto absoluto, y nadie se percató de lo ocurrido.

La segunda reunión tuvo lugar en la sede de La Patria que suspendió sus sesiones el día 10, para notificar "a sus hijos" que el 14, día del remate, la mesa directiva iría a bordo del Blanco Encalada, a las 10 1/2 A. M.; y que la población recibiría las órdenes del caso a las $111 / 2$, es decir media hora antes de la subasta. Mientras tanto, todo el mundo debía continuar tranquilamente en su trabajo cotidiano.

"En la noche del 10, tuvo lugar un incidente, que pudo haber originado graves consecuencias. Cuando la población estaba sobre un volcán, don Mateo Concha Moreno, antiguo vecino, entusiasta chileno, pero hombre curioso y noticiero de oficio, casi hace saltar la mina y pone sobre aviso a las autoridades [bolivianas]. Don Mateo tuvo conocimiento de la reunión celebrada en casa de don Matías Rojas, a la que no fue invitado, precisamente por su fácil lengua. Esto le tenía resentido; y como había visto llegar banderolas y cohetes, disimuladamente, a la Compañía, se le avivó en grado supremo la proverbial curiosidad. Atando cabos, dando y cavando, columbra que algo se trama y trata de inquirirlo, con la mejor fe del mundo. En la noche M 10, el Club rebosa de gente; todas las conversaciones giran alrededor de la cuestión del día, en la certeza de que algo crudo puede ocurrir. Llega don Mateo al círculo en que charla don Matías Rojas, se dirige a él y le dice, alarmado: ¿qué significan, paisano, unos voladores que están disparando en la Compañía?" (Machuca, 1926: 31).

En efecto, el pueblo armado estaba impaciente. George Hicks le dice a los Sres. Miller y Adamson de la CSFA: "podríamos tomar el lugar en diez minutos si solo Chile lo autoriza$r a$ ” " "Un solo cañonazo o una corrida de nuestra gente los haría volar. Chile no debería titubear en retomar este territorio" (Querejazu, 1979: 233).

Prosigue Machuca, de primera mano:

"El 12 y el 13 la tensión nerviosa es terrible; nadie trabaja; la población vive en la calle; el comercio cierra sus puertas y el movimiento de la bahía se paraliza; siniestros rumores circulan entre los grupos; noticias inverosímiles corren de boca en boca; la columna de gendarmes permanece acuartelada; y destacamentos, bayoneta armada y bala en boca, custodian la prefectura, la aduana y el cuartel. [...] Jamás se había notado mayor calma en la población; pero en las casas, las mujeres afilaban los corvos a molejón y preparaban banderas chilenas, en tanto los hombres discurrían la mejor manera de secundar las órdenes de La Patria, que seguramente afrontaría la situación en el momento preciso" (Machuca, 1926: 32).

Cuando el peruano Paz Soldán ofreció sus buenos oficios al Ministro de Relaciones 
Exteriores era ya demasiado tarde: Daza había rescindido las concesiones de la CSFA. El 14 de Febrero, Paz Soldán le comunica a Irigoyen, Ministro de Relaciones Exteriores del Perú, el resultado de una nueva conferencia tenida con el Ministro chileno quien rehusó nuevamente los buenos oficios, considerando que Bolivia trataba sólo de ganar tiempo para movilizar sus tropas. "Chile necesita resguardar los intereses de sus nacionales y ocupará hasta el grado 23; y si Bolivia no vuelve sobre sus pasos, retrotrae nuestro pleito [limítrofe] al estado anterior del tratado de 1866" (Machuca, 1926: 84).

“Quizás" -dice Paz Soldán, lejos de imaginar el alcance de lo ocurrido el 14 de Febrero- "a su Gobierno, la ocupación del litoral, no tenga por lo pronto, más objeto que custodiar las propiedades chilenas, e impedir un saqueo, que es lo que constantemente ha aparentado temer este Gobierno".

\section{Concluyendo}

Es cierto que las finanzas europeas allegaron sus guerras imperiales al teatro periférico que venían levantado en el Desierto de Tarapacá y Atacama. Pero no es menos evidente que cuicos, cholos y rotos protagonizaron una guerra civil mestiza, propia, regional, comercial e industrial, en una clave racial que resulta difícil de explicar en términos europeos, de blanco y negro. Ciertamente, a la moda imperial, en Chile el poder político-económico fusionó con el militar y esta élite se asoció en la guerra a la clase popular en torno a un proyecto de "re-conquista" nacional. Paradójicamente, aunque la Guerra del Pacífico fue una guerra expansiva que ancló más fuertemente a Chile en la esfera capitalista, también reveló un histrión geopolítico a tomar en cuenta en esos tiempos de redibujo internacional, en los que los imperios (se) hacían y deshacían vertiginosamente por el control de más territorios, cada uno a su característica manera.

Vimos que el ambiente revolucionario de Antofagasta animado por La Patria y la CSFA, gravitó en la mente de los estadistas chilenos a la hora de decidir la guerra. El asunto se enrieló por supuesto en beneficio del genio financiero de los Edwards, controladores de la CFSA e impulsores materiales de la guerra, duchos en el juego económico imperial transnacionalizado que caracterizó el fin de siglo. La guerra de los Edwards no solamente posibilitaba sino que suponía y exigía, la continuidad de los ingresos mineros para la CFSA mientras durara el conflicto: los ingresos del salitre debían seguir fluyendo, y lógicamente, los Edwards se debían de adelantar fondos para asegurar que esto fuera así, mientras duraran las hostilidades. Las vinculaciones y operaciones de la oligarquía militar-industrial fueron evidentes. Así lo proclama Sotomayor:

“¿Qué importan los disgustos del pasado si el presente y el porvenir de este suelo es nuestro? Una vez más: orden y moderación. ¡Viva el Gobierno de Chile que ha sabido interpretar los sentimientos de los industriales chilenos que tanto han padecido bajo el dominio boliviano!" (Proclama de Emilio Sotomayor en Antofagasta, 14 de Febrero de 1879).

Aunque la CFSA aprovisionó gustosamente a la fuerza chilena que desembarcó con las mercaderías que se encontraban en sus bodegas y pulperías, rehusó hacerlo a su costa, por ser aquello 'ajeno a su giro'. Con todo:

"animado el Consejo Directivo [de la CFSA] del deseo de prestar todos los servicios que las circunstancias exijen del patriotismo de todos los Chilenos, la compañía se prestará gustosa a suministrar de su propia provisión, todos los elementos que sean necesarios para el mantenimiento de las fuerzas destacadas 
en el Litoral a los precios de costo para ella' aclarando con finura mercantil, que lo haría 'renunciando a toda comisión o retribución durante le tiempo que el Supremo Gobierno necesita para organizar este servicio” (AM-ARE 443-1, fs. 68).

Pero el ejército necesitaba además espacio suficiente para albergarse y entrenar a las tropas que llegaban del sur: los mismos patios de la CSFA se transformaron rápidamente en campamento y rancho. En alguna ocasión hubo 18 mil soldados (Recabarren, 2002). El 19 de marzo, la CFSA le presta 500.000 pesos en billetes al ejército: el problema logístico no era menor ¿De dónde sacar físicamente el dinero para pagar el rancho de la tropa y el alquiler de las carretas que debían transportar de inmediato el material y las tropas de Antofagasta a Caracoles?

Su controlador, Agustín Edwards Ossandón, junto al Partido Nacional o monttvarista, se revelan aquí como el nervio sui generis del imperialismo criollo desatado en el Desierto boliviano, oportunamente aliados con los radicales y la masonería: la campaña chilena era impensable sin el apoyo material y logístico de esa gran fortuna, y su incomparable influencia política. Fue Cornelio Saavedra, accionista de la CFSA, quien ordenó, concretamente, la toma de Mejillones, Cobija y Tocopilla "para proteger a los chilenos residentes" (ocupando el litoral). Desde Tocopilla partieron luego algunos cuerpos de tropa a destruir 3 de los 4 puentes que cruzaban el Río Loa en Chacance, rumbo a Calama. La idea era cerrarle el camino a los eventuales refuerzos bolivianos. Posesionándose de la salitrera de El Toco y del oasis de Quillagua, el ejército selló también las posibles vías de aprovisionamiento desde el Perú. Asegurada la línea del Loa hasta Quillagua, los escasos resistentes bolivianos se agruparon en Calama.

Cuando la línea sur de las tropas de tierra al mando del oficial Joaquín Cortés llegó a Caracoles, la fuerza boliviana de la plaza ya se había entregado a Ramón Espech y los demás chilenos que pronto integraron su "batallón cívico". La orden que recibió Cortés, el mismo día 14 de febrero, revela la claridad de propósito con que actuaba el mando político-militar. Él debía:

"nombrar comisión de vecinos respetados que se reciban de los archivos y oficinas bajo inventario general, i un depositario que los custodie. Como Ud. lo comprende, interesa sumamente que se salven esos archivos íntegros" (Ahumada, 1885: 120).

Evidentemente, el registro de estacas y otros papeles argentíferos debían protegerse a toda costa, y fueron objeto de las primeras providencias de los accionistas-militares a cargo.

Tras la toma de Calama el 23 de marzo, siguió una guerra de posiciones con diversos enfrentamientos en la línea del Loa, los chilenos en trayectoria ascendente hacia el Noreste, hasta Canchas Blancas, dirigida a proteger los emprendimientos minerales en Huanchaca, Oruro y Corocoro, donde las oligarquías de Bolivia y Chile compartían fuertes intereses ${ }^{16}$. Con la ocupación de Quillagua, efectuada conjuntamente a la de Calama, quedó finalmente bajo poderío chileno toda la línea del Loa (Barros 2008). Fuerzas adicionales se dirigieron

16 La mina de plata de Huanchaca, que en 1877 ocupaba 1.567 obreros, contaba entre sus accionistas al chileno Melchor de Concha y Toro que tenía 355 acciones, Elías y Ezequiel Balmaceda con 125 acciones, Ramón y Gregorio Donoso con 95 acciones y Rafael Larraín con 35 acciones. Cada acción valía 1.000 pesos. Por razones evidentes, ellos no fueron partidarios de la Guerra, y así, parta del empeño militar chileno consistió en apaciguarlos, y asegurar los intereses chilenos allí y en Corocoro. Entre los accionistas bolivianos, Querejazu señal a Aniceto Arce, Francisco Argandoña, Peró Hermanos, Dorado Hermanos y otros. Cabe que Aniceto Arce haya sido el misterioso "caudillo boliviano" que se prestó para el juego de La Patria, y no Ladislao Cabrera, "Héroe de Calama" -como descarta el propio Benjamín Vicuña. 
hacia el sur, a San Pedro de Atacama, con el fin de cerrar los caminos con Argentina e impedir el abastecimiento desde ese frente.

\section{Conclusión}

"I no sin objeto ponemos al roto frente del cholo, porque aquél es la humana antítesis del último. No llega nuestra ciencia... hasta trazar el oríjen ni la significacion del cholo, que es el roto manso del Perú. Pero nadie ignora que porque en Chile se acorta

i se acobarda, sea delante del corvo o sea delante de simple sarcasmo, dícese que se acholó... es decir, que dejeneró de su altiva raza a inferior estirpe. Por manera que lo único que han hecho los cholos... en presencia de nuestros rotos de hoi, es simplemente acholarse, i así se acholará mañana la chola Lima i la brava jente que la defiende... que todo no es sino una sola $\mathrm{i}$ mísera "cholada" (En Vicuña, 1880b: Cap. 13).

Algunos autores consideran que el discurso racializado del imaginario público chileno respecto a los bolivianos y peruanos en la Guerra del Pacífico, fue una suerte de pantomima periférica del discurso imperial decimonónico importado de Europa -considerado implícitamente como centro de producción histórica wallersteiniana (Beckman, 2009). Otros autores suponen erradamente que el racismo sólo apareció en Chile bajo la influencia prusiana en el ejército, atraída por Boonen y Körner a partir de 1884 -cuyos efectos se aprecian especialmente tras la Revolución de 1891.

Pero vemos que apenas desencadenados los hechos de la guerra (Borras), los textos bolivianos denuncian racializadamente la agresión chilena. Los titulares de la primera página de El Comercio de La Paz, con fecha 28 de febrero de 1879, del que ofrecemos un extracto, dan una idea del estado de ánimo de parte de la población : "Mejillones y Caracoles en Poder del invasor - El filibusterismo araucano - Criminal ocupación del litoral por las fuerzas chilenas".

"¡Mueran los cobardes araucanos, porque su puñal ha rasgado nuestra hermosa tricolor, porque salvajes han consumado el crimen más infame en el suelo bendito de la patria!"

Las referencias sobre límites argumentadas con rigor jurídico pasaron a un segundo plano, abriéndose paso un discurso emocional destinado a galvanizar la sagrada unión nacional

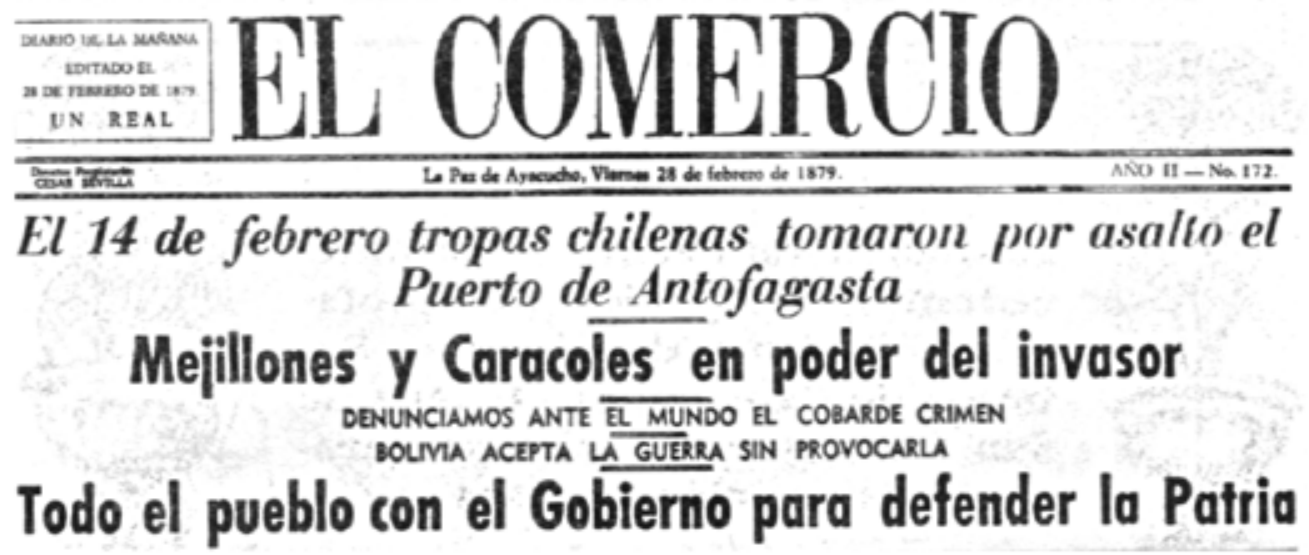


entre la oligarquía y el pueblo: "Todo el pueblo con el Gobierno para defender la Patria".

Carrión compone también una marcha para piano "Odio a muerte a Chile" lo que nos da una idea de los sentimientos que animaban a la población peruana respecto de Chile. Otras marineras se refieren al conflicto, una de las más conocidas compuesta por José Alvaradito, lo dice todo: Ya no te quiero chilena:

Ya no te quiero chilena porque me causa recelo tu conducta, nada buena, y el juego de tu ciruela.

Aunque en rica canasta me des ciruelas, con lo de Antofagasta, me desconsuelas.

Me desconsuelas Ñata corre, ve y dile que por las salitreras da un ojo Chile.

¡Caracoles si comba este toro saldrá bomba! Piénsese también en la marinera La Antofagasta:

Ven acá, sol de mi vida ven "salitrera" de mi alma que aunque tu madre no quiera tú serás mi "Antofagasta" Desde que te he dado un beso en ese tu lindo pico no me importan tus padres, negra, te reivindico.

Te reivindico, Nata

Flor de canela, cofrecito de alhajas, mi "salitrera".

Que sí, que no, que cuándo. Ya voy que me están peinando.

Mientras que vienen por tí, déjame comerte a besos; ámame cielo sin nubes que después emplumaremos.

Déjame mirar tus ojos de mi amor, blanca azucena; ábreme tu corazón que allí están mis "salitreras". 
Que sí, que no, que cuándo.

Ya voy que me están peinando.

Ciertamente, el discurso racista y xenófobo que circulaba por las prensas latinoamericanas se formó mucho antes de la Guerra del Pacífico. Creció con el lenguaje transmitido por la oligarquía criolla que se imaginaba en tanto encarnación racializada y parte de una élite de carácter transnacional. Tanto en Chile como en Bolivia, esta élite criolla, empleó al Indio estereotípico de la colonia para estigmatizar a los "hermanos" criollos, hermanos que se fueron diferenciando entre sí con cada vez mayor violencia tras la las Independencias.

En otra parte hemos abordado ya este cariz de las guerras en las que ha participado Chile, así como el ambiente racializado y xenofóbico que prefiguró la Guerra del Pacífico, y que estuvo también presente en la primer desembarco militar chileno en el Litoral boliviano, en 1836 (Barros, 2008a, 2009). Sin duda que la influencia tecnológica europea y la meta-narrativa frescamente impresa, de tinte imperial y colonialista, moldeó fuertemente las opiniones públicas chilenas de la época. Pero existía también una prensa regional rica y variada.

No es menos cierto que tropas chilenas ya habían desembarcado en Cobija el año 1836, en contra de la Confederación Perú-boliviana del Mariscal Andrés de Santa Cruz y Calaumana, y claramente no fue para copiar alguna guerra europea: el racismo nacionalizado de los criollos ya tenía un sello propiamente sudamericano (Capdevila, 2007). Por eso Portales sonsacó la alianza Argentina, para asegurar la hegemonía comercial de Chile en el Pacífico sur, y contrarrestar los brotes recurrentes de imperialismo provenientes del exVirreinato peruano, Alto y Bajo, desde que la Expedición Libertadora pasara por Lima. El plan era frustrar la reconstitución del Tawantinsuyo incaico que ambicionaba el Mariscal Santa Cruz (Vid. Barros, 2009). El mismo móvil geopolítico contra la Confederación Perú-boliviana despertó al genio guerrero surandino en la segunda mitad del siglo XIX, cuando la costumbre colonial racista y xenofóbica (anti-francesa, anti-inglesa) se hizo más densa y cristalizó en la muerte, dada en el "Teatro de la Guerra".

En ambas guerras se emplearon dispositivos discursivos de raza, pero los sentimientos xenofóbicos sudamericanos propiamente tales, solo se pronunciaron entre sus élites, en las postrimerías de la Guerra contra España (1866). Luego, la extravagante bonanza salitrera regional y luego, argentífera, de Caracoles, fue, como siempre, terreno fértil, con su cadencia de migraciones y la explosión de periódicos: Si 40 años antes las abigarradas castas comerciales de las ex colonias del Pacífico se disputaban la hegemonía del Callao, Cobija o Valparaíso; en la era de la segunda revolución industrial y nueva fase de globalización capitalista, la guerra estuvo materialmente ligada a la expansión de la agricultura y de la industrialización armamentista en Europa, Estados Unidos y Japón: los nitratos del desierto eran su abono y su pólvora.

La elite económica chilena no se podía dar el lujo de abandonar su nicho minero-comercial, hábil y trabajosamente conquistado en la explotación del salitre boliviano, ni menos, permitir su entrega al gobierno del Perú (Ortega, 2004). No solamente por dinero, sino que tal vez por lo que Ravest gusta en llamar 'honor', competitividad imaginaria sin duda asociada a la opinión pública en manos de una prensa ciertamente nacionalizada y (mal) aprontada para la guerra, al estilo imperial. El punto es que la Guerra del Pacífico detuvo en seco la hegemonización peruana del mercado mundial del salitre y el yodo, consolidando temporalmente una combinación financiera chileno-británica, deshecha luego de la conocida "desnacionalización" del salitre y el férreo reinado monopólico -en todo semejante a la que hubiera querido para sí la elite del Perú- aunque bajo un nuevo Rey, inglés esta vez, Thomas North (para un análisis del efecto del monopolio de North en los ferrocarriles de Tarapacá, ver Barros, 2005).

No fue el empuje machista, racista y xenofóbico anti-boliviano y anti-peruano de la sociedad La Patria y de la CFSA, lo que determinó el estallido de la guerra, pero no es menos 
cierto que las actividades asociativas y la publicación y exacerbación de los enfrentamientos constantes de la población civil con la policía boliviana predispusieron a la opinión pública chilena para la guerra de ocupación y anexión territorial - como indirecta satisfacción populista ante el chasco militar con Argentina por la Patagonia, que la prensa denostó tendenciosamente, avivando los tizones de la guerra.

Mediante una campaña de prensa efectiva entre una masa laboral dependiente, se fue generando el más poderoso argumento justificativo, de que la ocupación del Litoral protegía la población civil chilena en contra de los abusos bolivianos. Pero también, de que Chile no iba a dejar así nomás que sus vecinos los pauteara sin respeto.

El uso concertado de señales, voladeros y luces de guerra entre los habitantes de Antofagasta, demuestra que los partidarios de la ocupación supieron sincronizar los intereses de su propia revolución insurgente, con los intereses financieros de la CFSA para la guerra internacional, elementos aglutinados entre otros, por el discurso xenofóbico. La odiosidad de clases y conflictos sociales que asoman en los textos que hemos reseñado, se transmutaron en guerra internacional liderada por las respectivas oligarquías nacionales, asociada a la fiebre financiera que se desató en Europa, y alcanzó a Chile con subidas apuestas especulativas colocadas sobre la victoria de uno u otro bando.

Visto así, el relato de Vicuña Mackenna se desnuda en forma contradictoria. Por un lado, muestra la guerra como una acción popular y libertaria, de combate revolucionario de las masas trabajadoras contra la tiranía opresora, haciendo honor al ancestro mapuche y al roto chileno. Pero también ensalza la guerra de conquista civilizatoria y de elite, basada ciertamente en la superioridad racial y tecnológica del "roto", pero también en el genio superior de "su" elite blanca. El periodismo liberal del Nuevo Ferrocarril contribuyó así, equívocamente a la "Lucha entre las Razas" postcoloniales, para luego minimizarla a favor de una noción de superioridad de clase, o idea de una acción nacional cívica e ilustrada, en contra de la tiranía policial boliviana que sometía indirectamente a los chilenos al servicio del bárbaro imperialismo peruano, peruano que tras ser derrotado y en adelante sería "popularmente" clasificado y denostado como "muerto de hambre".

Así también, las comunidades e individuos indígenas de carne y hueso, atacameños kunza-hablantes en su mayoría, pero también de tradición quechua y aymara, aparecen y desaparecen misteriosamente de este esquema discursivo de la guerra, paradójicamente, en los márgenes de la historiografía. Por un lado son tratadas como víctimas de su inferioridad racial inmanente -y por lo tanto justamente sometidos y derrotados- a la vez que son presentados como inocentes criaturas ajenas a la guerra, masa ignorante que había que liberar del yugo boliviano.

El indiecito pastor del altiplano que masca coca y come maíz tostado, pasó a ser el Indio nacionalizado como enemigo del chileno, demonizado por la prensa que proyectaba sus propias pesadillas en torno al holocausto que avalaba simultáneamente al sur del Bío-Bío. En efecto, para Vicuña, las razas en pugna no eran la blanca contra la indígena. Para él, la guerra fue indudablemente mestiza, entre estirpes criollas postcoloniales imaginadas como mezclas desiguales entre indígenas y blancos. ${ }^{17}$ Pero para poder estigmatizar al mestizo enemigo, y envilecer metonímicamente sea al 'cholo', 'cuico' o el 'roto', los escritos de la guerra echan mano al estereotipo del Indio. Este llamado contradictorio, de amor y de odio racializado, no fue resuelto por la Guerra, todo lo contrario: en Bolivia, las castas indígenas selváticas, serranas o puneñas fueron momentáneamente invisibilizadas por la guerra, no civilizadas. Así, para la fortuna de los atacameños, aunque crecientemente sometidas y expoliadas en los hechos y el derecho, la efectiva confiscación y remate de tierras comuni-

17 Según Portales, el mestizaje en Chile habría sido mucho mayor que en Perú y Bolivia: él veía que el mayor número de población blanca y educada en esos países también amenazaba las posibilidades hegemónicas de Chile (Barros 2009). 
tarias indígenas solo comenzó en Bolivia en el año 1880, cuando la Región de Antofagasta estaba ya en poder chileno, y así, no tuvo efectos en el territorio atacameño (Barros 2004, 2008a y 2008b). Es más, los comuneros de algunos ayllu atacameños se sumaron a las tropas chilenas para proteger sus tierras ante los abusos del gobierno boliviano. ${ }^{18}$

La raza sudamericana del "roto" chileno resurgió así, estereotípicamente, como (r)evolución de otrora invencibles araucanos con atrevida soldadesca española, ambos sublimados en la figura del "roto" chileno-araucano de Yungay. En la guerra, el mestizo boliviano-aymara o "cuico" y el "cholo" peruano-quechua, conformaban la carne mestiza de la que debía alimentarse el espectro internacional, tal como lo grafica un exaltado Vicuña Mackenna:

"el roto... corresponde al lépero de Méjico, al llanero de Venezuela, al montuvio del Ecuador, al cholo del Perú, al cuico de Bolivia, al gaucho de las Pampas i al huaso mismo de nuestra tierra, porque en realidad el roto no es sino el "huaso a pié" (Vicuña 1880b: Cap. VI).

Incluso el genial y austero caballero que fue Alberto Blest Gana, defendiendo ante el Presidente Santa María la calidad del armamento francés que venía adquiriendo y despachaba a Chile, desde su puesto de Embajador en Francia, decía:

"y ahí tiene Ud. ahora al [fusil] Comblain matando cholos y cuicos que da miedo..."19.

Las tropas chilenas practicaron con orgullo tácticas de guerrilla aprendidas en las masacres cometidas y padecidas al sur del Bío-Bío, en la guerra chileno-mapuche. El "roto" chileno confirmó con ello su vocación expansiva, ya no solo como huaso errante de a pie, miliciano o carabinero de frontera en territorio mapuche, sino que como minero andariego o contrabandista infatigable por tierras de indios veleidosos y taciturnos -esta última, fabricación identitaria propia del Norte Grande que tomaría cuerpo en el "pampino" y en menor medida, en el "arriero", ambos con semejanzas con el "pionero" norteamericano.

La guerra del Pacífico fue entre excolonias criollas que formaban la nueva élite de un mismo continente. Salvo contadas excepciones, el Indio era un recurso discursivo para (desy re-)clasificar e insultarse mutuamente por medio del antiguo código de castas colonial, que al transponerse en el conflicto comercial y la guerra social sudamericana, lograba subvertir los esquemas de dominación compartidos por Bolivia y Perú, que Chile se resistía a aceptar, desdibujándolos. Todos le decían Indio al mestizo enemigo, mientras los pueblos indígenas se dejaban ver solo marginalmente en los hechos de armas (hasta la larga campaña en la sierra peruana, en que los indígenas hastiados de ser expoliados por tropas de uno y otro bando, comenzaron lo que el Cónsul de Francia en Lima describe como una verdadera "guerra de razas", en que los indígenas de la Sierra exterminaban a todos los blancos que se ponían a su alcance, sin distinción de nacionalidad).

Pero la Guerra del Pacífico fue ante todo entre intereses comerciales inter-oligárquicos sudamericanos y euroestadunidenses, aderezada de lenguaje legitimante militarista, guerrero, nacional, popular y racista. Con retazos napoleónicos trasnochados y en emulación de la figura ascendente de Bismarck, el discurso nacional chileno participó de la ideología geopolítica colonialista de la civilización contra la barbarie, vigente en Europa. Pero estos términos fueron apropiados y re-desplegados en el particular contexto postcolonial del mestizaje latinoamericano, conforme a antiguas lógicas endógenas de diferenciación socio-

$18 \mathrm{La}$ actividad indígena atacameña durante la guerra se detalla en otro artículo pronto a publicarse. 19 “Archivo Santa María” (C 4303 AE) Archivo Nacional. 
territorial, en las que el poder se distribuía desigualmente, en castas y jerarquías estratificadas racialmente.

Las guerras de razas, intuía Vicuña Mackenna, no eran más que la contracara de sordas guerras financieras entre las élites:

'Sabido es de todos que la eterna guerra de Arauco -que será tan eterna como la del Perú, si ésta ha de convertirse en guerra de negocio, trocando indios por salitre i chinos por azúcar- consumió en el primer siglo de su existencia (cuyas postreras i crueles pero previstas vibraciones está trasmitiendo en estos momentos el telégrafo)" (Vicuña, 1880b: Cap. 8)

Vicuña sabía que las crisis geopolíticas, económicas y migratorias se relacionan cíclicamente a través de discursos identitarios colectivos territorializados. Hijas del capitalismo de imprenta y de las modernas tecnologías de la guerra, vimos esas complejas asociaciones conspirar, como La Patria, la CSFA, la Armada de Chile y la misma municipalidad de Antofagasta, para fusionar brevemente con la cúpula financiera y militar chilena, en una orgía de guerra.

Aunque sin duda merece mayor estudio, pareciera que la revolución de 1891 también puso fin en Antofagasta, al incipiente regionalismo popular de las décadas previas. Antofagasta no quedó para siempre bajo el mando de los Zenteno, Hicks y Villegas. Tras la "desnacionalización” del salitre en 1891 (ver la discusión en Ravest, 2008a: 66 y ss), la geopoïética e identidad nacional-popular de organizaciones regionales como La Patria sería poco a poco deshilvanada, material y simbólicamente, especialmente tras los primeros despidos de la crisis del salitre, con las masacres de Plaza Colón en 1906 y de la Oficina San Gregorio en 1926. Es preciso entender que las versiones de pioneros y autóctonos, indígenas y/o regionales de comunidades imaginadas autónomamente, nunca fueron toleradas por mucho tiempo por la elite centralista ${ }^{20}$.

Queda que la acción colectiva de esas corporaciones antofagastinas de pre-guerra fueron prácticamente eliminadas de la historiografía nacional de la post-guerra. Por eso, importaba rescatarla, para la memoria social. Ésta fue reemplazada por dispositivos de memoria militaristas centralizados, de aparato y cartón, por numerosos mitos de guerras y clanes descontexualizados -comúnmente, al servicio del Estado oligárquico, abstracto y timorato, para hacer olvidar a toda costa que el Litoral fue boliviano alguna vez, y que los chilenos que allí habitaban, lo conquistaron "a la criolla", mediante presiones, revoluciones y aprestos.

En relación con lo anterior, y siendo que su libro es considerado una pieza fundamental de la historiografía de Antofagasta, es notable que Isaac Arce, a diferencia de Vicuña y Machuca, mencionase La Patria tan solo una vez en su libro y al crucial Villegas, apenas al pasar $(1930,431)$, probablemente por haber sido un ardiente balmacedista. Tal vez esto se relacione también con que Arce hiciera caso omiso de las masacres obreras de 1906 y 1927 en la región.

Los aspectos colectivos más difusos o populares son, precisamente, los que permiten superar la binaridad del esquema disciplinario tradicional-centralista, conforme al cual se suele representar esta guerra como función de títeres "de la periferia capitalista euroestadunidense". La microhistoria de la sociedad Litoral de pre-guerra -la autoreferencia regionali-

20 A principios del s. 20, se crearon organizaciones civiles ultra-nacionalistas chilenas en Arica, Tacna y Tarapacá, denominadas ligas patrióticas, con nombres tales como "Mano Negra", "Mazorqueros", "Sociedad Estrella de Chile", "Liga Patriótica de Tacna", persiguieron a los peruanos incendiando casas, escuelas, diarios, clubes, comercios Los paramilitares, bajo un supuesto amparo del gobierno, cometieron asesinatos, desapariciones, y expulsaron a habitantes peruanos. Promovieron sus acciones a través de pasquines tales como "El Eco Patrio", "El Ajicito", "El Corvo", "El Roto Chileno", "La Liga Patriótica", "El Chileno", "El Lucas Gómez", "El Plebiscito". El gobierno de Chile intentó disolver estas organizaciones en 1912, pero no logró su objetivo. 
zada de sus jóvenes creencias, valores y actitudes- permite enfocar más allá de la tradicional retórica de oposición entre Chile, Bolivia, Perú, y Argentina, por cierto, o entre civilización y barbarie, ciudad y campo, indígena y no-indígena; esto, para entender el proceso efectivamente, en toda su complejidad territorializada y propiamente social.

La suerte de inevitabilidad (retrospectiva y anacrónica) que subyace a la idea de una guerra capitalista por procuración, eclipsa de manera etnocéntrica el carácter popular, regional y nacional, diplomático, fáctico, progresivo y territorializado del avance colonizador criollo chileno en el Desierto de Atacama. Esa masa laboriosa imbuida de nociones de honor y masculinidad, características del romanticismo liberal decimonónico, venía siendo recortada y estigmatizada racialmente por los escritos que prefiguraron la guerra de razas, haciéndola posible. La versión de que ésta fue una guerra periférica menosprecia el poder endógeno y endópeto del racismo como discurso universalizante primero -y luego, el de la xenofobia racializada- que todos los beligerantes compartían en el nivel del discurso público, cada uno de ellos, como un código cultural común brotado de la raíz esclavista y genocida colonial, mercantilista y encastada, re-significando las antiguas categorías raciales en la escala mayor sudamericana, como naciones criollas en pugna, aunque con las mismas connotaciones raciales de la época colonial.

El clasismo, el racismo y la xenofobia siguen siendo los más tenaces elementos de la (anti)sociabilidad latinoamericana y chilena, donde casi todos los países se dan la espalda, por dentro y por fuera (Barros, 2008b). Por eso, las identidades en pugna de esta guerra tan típicamente americana no deben remitirse al solo 'teatro bélico periférico' de un primer mundo que guerreaba sin tregua. La Guerra del Pacífico no fue una puesta en escena postmoderna, y pierde con leerse en clave exclusivamente performativa, como "suplantación imperial racista" (donde las sociedades representan y actualizan diferencias colectivas simbólicas en función de dominar recursos materiales limitados) ${ }^{21}$. Porque sin perjuicio de que el sentimiento nacional chileno de la guerra terminó trabajando a favor de la oligarquía chilena, es evidente que tanto La Patria, como la CFSA o el gobierno de Santiago de la época, no se limitaron a imitar los centros imperiales euroestadunidenses, ni fueron meros títeres de guerra en la periferia del capitalismo. En efecto, el expansionismo chileno hacia el Norte no es un mero remedo del imperial, ni ataca sistemáticamente a pueblos considerados y tratados como inferiores por diferentes, como lo hacían los países europeos en África y Asia (Manceron, 2007). La guerra del Pacífico, aunque puede pensarse como guerra internacional de expansión colonial chilena, fue ante todo, civil, entre criollos "hermanos sudamericanos" que hasta hace poco (1866) habían enfrentado juntos el terco poder español. Las diferencias, racializadas por los textos que prefiguran la guerra, se volvieron pronto estigmas nacionales.

Aunque retomó algunos de los temas de la expansión capitalista entonces en boga en Europa, el racismo xenofóbo chileno tenía -y mantiene- bases históricas autóctonas, patriarcales y militaristas, postcoloniales, fragmentadas y matizadas, incluso barrocas, donde las apelaciones Indio y Roto responden más a fenómenos forzados e insostenibles de clase, que de "raza", que es su subterfugio discursivo. Por eso, los inmigrantes europeos blancos, siempre han sido rápidamente asimilados. Así, los desdeñados Indios y Rotos son subsumidos retóricamente y naturalizados como a fenómenos de raza, justificándose así, metonímicamente, la pobreza india como cromatografía sacrificial chilena (Barros 2008b). El problema es que en un país miniatura como Chile, "todos nos conocemos" y no cabe cambiarse de vereda para obviar la desigualdad extrema, y esa desigualdad, convienen los expertos, es eminentemente racializada.

Finalmente, por qué no, el pulso de la guerra social en Antofagasta puede mirarse provechosamente en el contexto mental de una "lucha de razas" a la criolla, de orilla de cuenca

21 Ver Capdevila (2007) para una descripción del contexto global de las guerras americanas del s. XIX. 
Pacíficoamericana, de inspiración yankee y chilena, de pioneros afiebrados, de hombres y mujeres desnudos en el desierto. Eso le permitió a Vicuña Mackenna retratar la "independencia chilena" del Litoral como a la independencia californiana frente a México. Vicuña puso así en entredicho la versión nacional-centralista de la victoria en favor de una memoria más regionalista y popular, ciertamente más cercana a los hechos y sentimientos locales de la guerra. El tema merece mayor estudio: el movimiento asociativo liberal, reformista e incluso revolucionario de los chilenos en el Litoral boliviano, sacó importantes lecciones del pionerismo norteamericano en el norte de California, y sus discursos racializados en contra de mexicanos, californios y cholos, proceso que no se adscribe fácil ni completamente al programa de expansión imperial que se le atribuye a la élite (de hecho y contradictoriamente, Vicuña Mackenna fue partidario de México a la vez que gran admirador del empuje expansionista de los pioneros norteamericanos).

Los datos sobre la sociedad minera y financiera de pre-guerra muestran, más bien, a personajes y clanes semi-autónomos tomando decisiones y formando facciones movilizadas con trayectorias operativas propias (algunos, sin duda, replicando románticamente la imagen del franco-californiano, John Charles Frémont). Ahí estaban los obreros de cuadrilla y de fábrica, trabajadores cada vez más educados y organizados para la lucha contra el abuso laboral. Parafraseando al Marx del 18 Brumario, los que hicieron la guerra fueron mujeres, hombres y pueblos enteros, aunque sea en circunstancias que no eran de su elección. Por más que estuviera amarrada al carrusel imperial europeo, la guerra fue ante todo regional, nacional y sudamericana, teñida de un racismo colonial entretejido con sueños de dignidad social en el naciente horizonte sudamericano.

Así también, brevemente, la Guerra del Pacífico volvió a descentrar la identidad metropolitana chilena del pije y del huaso a pie y a caballo, dándole un nuevo sitial político de frontera al imaginario popular, así como al del migrante industrial, que no se atuvo al esquema mental imperial-centralista, sino que al pionerismo regionalista que surgió más allá de los límites territoriales chilenos, el "pampino" organizando acción colectiva autónoma en Antofagasta, "calichefornia" soñada.

La xenofobia contra los peruanos y los bolivianos que se observa hoy en el Norte Grande y en Chile, es particularmente clara en ese sentido: no solo fue la oligarquía chilena quien adquirió militarmente dos tercios del actual territorio nacional (un siglo y medio atrás), un verdadero emporio mineral. Lo hizo también "el pueblo trabajador", en busca de riquezas al alcance de su esfuerzo. La elite desarrolló su xenofobia en aras de su autonomía comercial y financiera civilizatoria, en un país con "destino minero" y, por fuerza, contra el afán hegemónico antiguo de Perú (de inspiración y raigambre incaica e imperial -o al menos virreinal). En este tira y afloja comercial y financiero, en el cono sur se aprecia que la falta de cohesión siempre va en excesivo favor del capital euroestadunidense.

Paladín de las libertades comerciales, históricamente y salvo honrosas excepciones, los gobernantes de Chile se miran a sí mismos como combatientes contra los afanes hegemónicos y monopólicos de sus vecinos, todos más grandes y poblados, indignos de confianza, como lo ha venido narrando la Historia. Internamente, conforme a su larga tradición militarista colonial, Chile también es un país donde los medios de la industria cultural mantiene la imagen del Indio estereotípico ávido de violencia, imagen que se presta fácilmente como preparación para la substitución xenófoba, como preparando una guerra, siguiendo los designios del capital financiero internacional.

Correlativamente, los sentimientos anti-chilenos están frescos en los imaginarios mediáticos nacionales que la Bolivia de Evo Morales y el Perú de Ollanta Humala y Alan García, mantienen respecto a los límites de las tierras y aguas de Arica, Tarapacá y Atacama que ambos países cedieron a Chile en 1883, 1904 y 1929. El expansionismo chileno tuvo un carácter propiamente popular y americano, enraizado en guerras interétnicas (Sur) y en el sistema de castas coloniales (Norte). Un contingente empobrecido de chilenos desnaciona- 
lizado inundó el desierto (como hormigas dice Querejazu) y se posesionó de él, adoptando el carácter mineral preñado de violencia y riqueza altamente (des)territorializada, confundiéndose todo, como si metiera la cola el dueño sobrenatural de la mina en los Andes, el supay, Tío, o diablo andino que parece a seguir dominando el paisaje social en Antofagasta, Región de la Minería ${ }^{22}$.

Hemos visto cómo el espíritu revolucionario chileno presente en el litoral boliviano escaló a guerra internacional en momentos cruciales de la bonanza del salitre y de la plata. La guerra es impensable sin las acciones de la La Patria y la CSFA; Chile como lo conocemos no existiría sin esa revolución que amagaron los pioneros nacional-regionalistas de $\mathrm{LaPa}$ tria con apoyo de la CSFA en el Litoral.

Las jóvenes repúblicas sudamericanas hoy sacuden nuevamente el polvo ensangrentado de sus viejos territorios, expandiendo la retórica identitaria limítrofe contra el telón de fondo post-colonial e indígena. Así se aprecia en el diferendo marítimo que Chile y Perú ventilan ante la Corte Internacional de La Haya, mientras Bolivia indígena ya no sabe a qué santo rezarle. Confiamos haber esbozado el horizonte de guerra nacional que existió y existe aún, en el intertexto racial actualizado por la memoriografía de la prensa chilena. En el discurso y en la práctica, el Indio sigue estando al centro racializado de la ecuación territorial xenófoba, aunque los marinos chilenos en un video filmado recientemente se entrenen entonando cantos xenófobos ("al argentino lo mataremos, al boliviano lo fusilaremos al peruano lo degollaremos"), y con excepción del argentino, que son "reconocidamente" superiores en términos raciales (porque más blancos), detrás de la máscara nacional, surgen los espectros raciales.

\title{
ANEXO I (Machuca 1926, 81)
}

\author{
Guardias Nacionales \\ Cuerpos cívicos bolivianos \\ Columna del Loa (trabajadores bolivianos de las salitreras)289 plazas. \\ Cuerpos cívicos chilenos improvisados en el Departamento de Antofagasta \\ Artillería \\ Brigada de Artillería de Antofagasta 95 \\ Infantería \\ Batallón movilizado de Antofagasta539 \\ Batallón $\mathrm{N}^{\circ} 2$ de Antofagasta763 \\ Batallón de las Salinas500 \\ Batallón de Caracoles665 \\ Brigada de Infantería de Mejillones 502612 \\ Caballería \\ Escuadrón Antofagasta 86
}

\section{ANEXO 2}

Señor coronel don Severino Zapata.

La Paz, febrero 6 de 1879

Querido amigo:

Tengo tus dos cartas del 26 del pasado que me es grato contestar.

Tu energía y rectitud en cumplimiento de las órdenes supremas me satisface, pues veo corresponderás con dignidad al honor nacional. No me cansaré de repetirte que tú tienes que ser el representan-

$22 \mathrm{El}$ movimiento asociativo 'mutualista' fue tempranamente poderoso en Antofagasta (Silva 2007, 245) 
te de la actitud del gobierno, y que como tal no cederás un solo paso.

Para probar a Chile que nosotros obramos con la justicia que nos acompaña y que no nos atemorizamos de sus amenazas con el Blanco Encalada, en consejo de gabinete se ha anulado el contrato sobre las salitreras con la casa inglesa para tener libertad de explotar por cuenta del gobierno, o arrendarlas conforme mejor convenga a los intereses del país. Espero que cumplas a este respecto las órdenes que se te comunican por el ministro de Hacienda.

Reservado. El ministro Reyes Ortiz marcha a Lima dentro de dos días a ponerse de acuerdo con el gobierno del Perú, a fin de que Chile, en caso de agresión, tener un enemigo a quien respetar, y arríe banderas como lo ha hecho con la Argentina. Debe igualmente pasar a ese Litoral y él te expresará las órdenes e instrucciones que por escrito se le han dado.

Me alegro que haya llegado Canseco para que te ayude en la conservación del orden público y sostenimiento de la dignidad nacional, y te autorizo y prevengo para que no admitas en ese departamento a cualquiera que lo creas sospechoso, bien sea contra el gobierno o en esta cuestión con Chile.

El país y las naciones limítrofes tienen fija la vista en tu actitud, y es preciso que sepas corresponder, como lo estas haciendo, al honor boliviano jamás mancillado.

Consérvate bueno y repútame siempre tu amigo.

H. DAZA".

(en Vicuña 1880a, 224).

\section{ANEXO 3}

\section{PROGRAMA DE LA SOCIEDAD «LA PATRIA.»}

La sociedad o club "La Patria" tiene por objeto la protección mutua de todos los asociados tanto en beneficio de sus intereses como de sus derechos y personas. Tendrá las sucursales que creyere conveniente. Ella prescinde de intervenir en la política del país y en las creencias religiosas de cada uno de sus miembros. En sus reuniones se prohíbe tratar sobre estas materias.

Todos los socios se someterán a las órdenes del Directorio, el que tendrá de parte de ellos las más amplias facultades para llenar el objeto de la sociedad.

Todo socio someterá forzosamente cualquiera cuestión comercial, de minas o personal quo tuviere con otro miembro, al fallo de un jurado de árbitros, nombrado del seno de la sociedad por los mismos interesados o por el directorio en subsidio. La sentencia que se pronuncie será de término.

La protección entre los socios consistirá, además, en procurar alivio al socio enfermo, ocupación al socio que de ella careciere y la defensa de sus derechos en conformidad con las leyes.

La cuota con que debe contribuir cada socio es de un peso mensual, sin perjuicio de la erogación voluntaria que a la incorporación o después, el socio quisiere hacer.

Se dictarán oportunamente reglamentos especiales o generales que se someterán a la aprobación de los socios reunidos.

Caracoles, octubre 19 de 1876.

(Vicuña 1880a, 52)

\section{REFERENCIAS}

\section{Fuentes primarias y documentos no publicados}

ANB-ECArchivo Nacional de Bolivia, Expedientes Coloniales

AN-AJAArchivo Nacional (Chile), Archivo Judicial de Antofagasta

AMArchivo Milita

\section{Fuentes Hemerográficas}

BGPBOLETÍN DE LA GUERRA DEL PACÍFICO 1879-1881. Re-editado por la Editorial Andrés Bello con ocasión del centenario de la Guerra. 


\section{Fuentes bibliográficas}

AHUMADA, P. (1885) Guerra del Pacífico. Recopilación completa de todos los documentos oficiales, correspondencias y demás publicaciones referentes a la guerra que ha dado a luz la prensa de Chile, Perú y Bolivia. Imprenta del Progreso, Valparaíso.

ASSIER-ANDRIEU, L.(1996) Le Droit dans les Sociétés Humaines. Paris, Nathan.

BARBIER, É. (1907) Un jeune pays du Pacifique: La Bolivie. Le Tour du Monde 13er año. Paris, Hachette.

BARROS, A. (1998) Desarrollo y Pachamama: Paisajes conflictivos en el Desierto de Atacama. Estudios Atacameños 13: 75-94.

(2004) Crónica de una etnia anunciada: nuevas perspectivas de investigación a diez años de promulgarse la ley indígena en San Pedro de Atacama', en Estudios Atacameños 27: 139-168. Antofagasta, U. Católica del Norte.

(2005) Monopolios sobre la infraestructura del transporte en la región del salitre y de la sal: Patillos 1870-1903 en Si Somos Americanos. Revista de Estudios Transfronterizos 7: 2 UNAP.

(2008a) Identidades y propiedades: transiciones territoriales en el s. 19 atacameño en Estudios Atacameños 35, 119-139, Antofagasta, U. Católica del Norte http://www.scielo.cl/pdf/eatacam/ n35/art07.pdf

(2008b) De las castas y la pobreza indígena en Chile, 2008. Anales del Instituto de Chile. $\mathrm{N}^{\circ} 27, \mathrm{La}$ pobreza en Chile II, Santiago, pp. 213-262.

(2009) La Guerra contra la Confederación Perú-Boliviana en el Distrito Litoral de Atacama'. In Donoso, C. s and Rosemblitt, J. (eds.) Guerra, Region y Nación: La Confederación PerúBoliviana 1836-1839. Universidad Andrés Bello-Centro de Investigaciones Diego Barros Arana.

BARROS, José Miguel (2008) Documentos sobre la misión confidencial de Arturo Prat en Montevideo: 1878-1879' en Boletín de la Academia Chilena de la Historia $\mathrm{N}^{\circ} 117,309-346$.

BENEDETTI, A. (comp.) (2003) Puna de Atacama. Sociedad, economía y frontera. Alción Editora, Córdoba.

(2005) Un territorio andino para un país pampeano. Geografía Histórica del Territorio de Los Andes (1900-1943) Universidad de Buenos Aires, facultad de Filosofía y Letras.

BRAVO, Carmen Gloria (2000) La flor del desierto. El mineral de Caracoles y su impacto en la economía chilena. Santiago: LOM-DIBAM-Centro de Investigaciones Diego Barros Arana.

(2008) La Plata de Caracoles : un capítulo de la historia boliviano-chilena. En García-Albarido et al. (eds.) El Mineral de Caracoles. Arqueología e Historia de un Distrito Minero de la Región de Antofagasta (1870-1989). Santiago, CONACULTA.

BRESSON, André (1875) Le Désert d'Atacama et Caracoles (Amérique du Sud). Le Tour du Monde V. XXIX, 321-352.

CAPDEVILA, Luc (2007) Une Guerre Totale Paraguay, 1864-1870. Essai d'histoire du temps présent, Rennes, PUR.

CAVIERES, Eduardo (2007) La construcción de los espacios: Significaciones económicas y conflictos nacionales: Bolivia, Chile y Perú, 1780-1840 en Eduardo Cavieres ed. Del Altiplano al desierto. La construcción de espacios y la gestación de un conflicto. Bolivia, Chile y Perú desde fines de la colonia a la primera mitad del s. XIX" Eudeva, Valparaíso.

CHAMBERS, S. (2003) Little middle ground: the instability of mestizo identity in the Andes, eighteenth and nineteenth century' en Appelbaum, N., Macpherson, A. y Rosemblatt K. (eds.), Race and Nation in Modern Latin America, Chapel Hill, North Carolina Press pp. 32-55.

CROZIER, Ronald (1993) La industria del Yodo 1815-1915. En Historia 27:141-212.

(1997) El salitre hasta la guerra del Pacífico: una revisión. En Historia 30:53-126.

CRUZ, Jorge (1966) Fundación de Antofagasta y su primera década. Ilustre Municipalidad de Antofagasta. Santiago: Editorial Universitaria.

DIRKS, Nicholas, 1987. The Hollow Crown: Ethnohistory of an Indian Kingdom. Cambridge, Cambridge University Press.

DOUGNAC, F. (1975). La legislación aplicable a los indígenas del Norte Grande chileno. Norte Grande 1 (3-4): 437-444.

EL NUEVO FERROCARRIL "Fisonomías del ejército aliado", 4 de diciembre de 1879, p. 3., citado en Beckman 2008 "Imperial Impersonations: Chilean Racism and the War of the Pacific" 
en e-misférica 5.2: Race and its Others (December 2008) www.emisferica.org

FABIAN, Johannes, 1983 Time and the Other: How Anthropology Makes its Object. New York, Columbia University Press.

GARCÍA-ALBARIDO, Francisco, Carmen Gloria Bravo, Francisco Rivera y Rodrigo Lorca (eds.) (2008) El Mineral de caracoles. Arqueología e Historia de un Distrito Minero de la Región de Antofagasta (1870-1989). Santiago - CONACULTA.

GELL, A. (1999) The technology of enchantment and the enchantment of technology in Hirsch, Eric (ed.) The Art of Anthropology: Essays and Diagrams/ Alfred Gell. London School of Economics Monographs on Social Anthropology Vol. 67. London, The Athlone Press.

GONZALEZ, José Antonio (2005) Chile y Bolivia, 1810-2000, en Pablo LACOSTE (comp.) Argentina, Chile y sus vecinos. Tomo I. Córdoba (Argentina), Caviar Bleu.

GREENHOUSE, C. (1996) A Moment's Notice: Time Politics across Cultures. Ithaca and London, Cornell University Press.

LATRILLE, Roch (1897) Notice sur le territoire compris entre Pisagua et Antofagasta, avec la région des hauts plateaux boliviens. En Bulletin de la Société de Géographie (Paris) 18, 473-495.

LÖFSTROM, William (1991) Cobija y el litoral boliviano. Visto por ojos extranjeros 1825-1880, La Paz,. Editorial Quipus/Verónica, Mauro Bertero.

MACHUCA, Francisco (1926) Las cuatro campañas de la Guerra del Pacífico. Valparaíso. Imprenta Victoria.

MANCERON, Gilles (2007) 1885 : Le tournant colonial de la République. Jules Ferry contre George Clemenceau, et autres affrontements parlementaires sur la conquête coloniale. Paris, La Découverte.

MESA, C. (1990) Presidentes de Bolivia: entre urnas y fusiles. La Paz: Gisbert

MESA, J. de, T. GISBERT y C. MESA (2007) Historia de Bolivia. Sexta Edición actualizada y aumentada. La Paz, Editoria Gisbert y Cía S.A.

MESSICK, B. (1993) The Calligraphic State: Textual Domination and History in a Muslim Society. Oxford, University of California Press.

O'BRIAN, Thomas (1980) The Antofagasta Company: a case study of peripheral capitalism”. Hispanic American Historial Review, Vol. 60, Nr.1.

ORTEGA, Luis (1984) Nitrates, chilean entrepreneurs and the War of the Pacific' Journal of Latin American Studies, v. 16: 2

(1984) Los empresarios, la política y la Guerra del Pacífico' en Contribuciones al Programa FLACSO N 24, Abril, Santiago de Chile, pp.77.

(2006) En torno a los Orígenes de La Guerra del Pacífico: Una visión desde la historia económica y social' in Asian Journal of Latin American Studies.

ORTEGA, Luis y Pablo Rubio (2006) La guerra civil de 1859 y los límites de la modernización en Atacama y Coquimbo' en Revista de Historia Social y de las Mentalidades No X, Vol. 2, 2006: 11-39

PAZ, G. (1991) Resistencia y rebelión campesina en la Puna de Jujuy, 1850-1875, en Boletín del Instituto de Historia Argentina y Americana "Dr. E. Ravignani” n. 4, Buenos Aires.

(1992) Campesinos, terratenientes y estado. Control de tierras y conflicto en la Puna de Jujuy a fines del siglo XIX, en Sociedad y articulación en las tierras altas jujeñas. Crisis terminal de un modelo de desarrollo. A. ISLA comp. Proyecto Ecira-edición MLAL, Buenos Aires.

PAZ-SOLDÁN, M. F. (1878) Verdaderos límites entre el Perú y Bolivia. Imprenta Liberal, Lima, Perú.

(1884) Narración Histórica de la Guerra de Chile contra el Perú y Bolivia. Buenos Aires, Imprenta y Librería de Mayo.

PHILIPPI, R. (1860) Viage al Desierto de Atacama Hecho de orden del Gobierno de Chile en el verano 1853-54, Halle en Sajonia, Librería de Eduardo Antón, Santiago de Chile.

RAIMONDI, A., (1879) El Perú. Vol. 3, Historia y Geografía. Imprenta del Estado, Lima.

RAVEST, Manuel (1983) La compañía salitrera y la ocupación de Antofagasta 1878-1879. Santiago de Chile, Editorial Andrés Bello.

(2008a) 'La Casa Gibbs y el monopolio salitrero peruano: 1876-1878', Historia $\mathrm{N}^{\circ}$ 41, I, pp 63-77

(2008b) 'La saga de las calicheras del Toco (1876-1924)' en Boletín de la Academia chilena de la Historia 117: pp. 191-245. 
RECABARREN, Juan Floreal (2002) Episodios de la Vida Regional. Ediciones Universitarias, Universidad Católica del Norte.

RUIZ-TAGLE, E. (1992) Bolivia y Chile: El conflicto del Pacífico. Editorial Andrés Bello, Santiago.

SATER, W. (2007) Andean Tragedy. Fighting the war of the Pacific, 1879-1884, University of Nebraska Press.

SILVA, Fernando (2007) 'El Chile liberal y los pobres' en Anales del Instituto de Chile V. XXVI, Estudios, la Pobreza en Chile I. Instituto de Chile, Santiago.

VALDIVIESO, Patricio (2004) Relaciones Chile-Bolivia-Perú: La Guerra del Pacífico en Relaciones Internacionales $\mathrm{N}^{\circ} 1$. En http://www.puc.cl/icp/eticapolitica/documentos/Relaciones\%20 Chile\%20Bolivia\%20Peru.PDF

VERGARA, Jorge Iván y Hans Gundermann (2007) 'El juego de las diferencias: de lo nacionalregional a lo regional-indígena. Una comparación entre Tarapacá y Los Lagos’ en Revista Austral de Ciencias Sociales 12: 31-56.

VICUÑA, Benjamín (1880a) Historia de la campaña de Tarapacá: desde la ocupación de Antofagasta hasta la proclamación de la dictadura en el Perú. Rafael Jover Editor, Santiago.

(1880b) 'El roto de Chile i su cuna histórica', en El Nuevo Ferrocarril, Santiago, 9 de diciembre de 1880. 